\title{
WestVirginiaUniversity
}

THE RESEARCH REPOSITORY @ WVU

Graduate Theses, Dissertations, and Problem Reports

2006

\section{Analysis of single-point test to determine skin factor}

Abbas Belyadi
West Virginia University

Follow this and additional works at: https://researchrepository.wvu.edu/etd

\section{Recommended Citation}

Belyadi, Abbas, "Analysis of single-point test to determine skin factor" (2006). Graduate Theses, Dissertations, and Problem Reports. 1759.

https://researchrepository.wvu.edu/etd/1759

This Thesis is protected by copyright and/or related rights. It has been brought to you by the The Research Repository @ WVU with permission from the rights-holder(s). You are free to use this Thesis in any way that is permitted by the copyright and related rights legislation that applies to your use. For other uses you must obtain permission from the rights-holder(s) directly, unless additional rights are indicated by a Creative Commons license in the record and/ or on the work itself. This Thesis has been accepted for inclusion in WVU Graduate Theses, Dissertations, and Problem Reports collection by an authorized administrator of The Research Repository @ WVU. For more information, please contact researchrepository@mail.wvu.edu. 


\author{
Abbas Belyadi
}

Thesis submitted to the

College of Engineering and Mineral Resources

at West Virginia University

in Partial fulfillment of the requirements

for the degree of

\author{
Master of Science \\ in \\ Petroleum and Natural Gas Engineering
}

Khashayar Aminian, Chair

Samuel Ameri, M.S.

Shahab Mohaghegh, Ph.D.

Department of Petroleum and Natural Gas Engineering

Morgantown, West Virginia

2006

Keywords: Single Point Test, Skin Factor, Permeability 


\section{ABSTRACT}

\section{ANALYSIS OF SINGLE-POINT TEST TO DETERMINE SKIN FACTOR Abbas Belyadi}

Single-point test results can be used to obtain information regarding the degree of damage in gas wells in the gas storage reservoirs. Single-point test is neither timeconsuming nor costly to determine the productivity of a well. Furthermore, flow stabilization times would be short in high permeability gas storage reservoirs. Generally, a four-point test is conducted first to establish the deliverability relation. After some period of time, namely one year, a single-point test could be conducted. The results of the single-point and four-point tests can then be compared in order to identify any alteration in well performance.

The objective of this research is to develop a methodology to determine skin factor by using a single-point test. In this work, the impact of formation permeability on determination of skin factor is studied for two cases, including transient radial and linear flow. The impact of non-Darcy flow is also considered in these cases.

The results of this study are summarized by a series of correlation to evaluate skin factor from a single-point test. 


\section{ACKNOWLEDGMENTS}

This thesis is the result of my journey in obtaining a Master's degree in Petroleum and Natural Gas Engineering. I would like to express my appreciation and gratitude to some people for helping me to make this thesis successful. First of all, I would like to express my gratefulness to my academic advisor Dr. Kashy Aminian, for his support over the last few years of my studies at West Virginia University. I really appreciate his help during my stay at WVU. His help meant a lot to me and it is memorable.

In addition, I would also like to extend my appreciation to Professor Sam Ameri, Chairman of the Petroleum and Natural Gas Engineering Department, for his support over the last few years at WVU. I am also grateful to Professor Sam Ameri for his participation in the examining committee.

Special thanks to Dr. Shahab Mohaghegh, for his consideration and patience during the past few years of my education at WVU. I am also grateful to Dr. Shahab for his participation in the examining committee.

Last, but not least, thanks are also due to my family members Dad, Mom, Fatemeh, Zeynab and Hossein for their support during my studies at WVU. Finally, I want to dedicate my thesis to my parents and older brother Ali, who passed away when we were younger. I will always love you, Ali. Most importantly, I would like to thank Allah for everything. 


\section{TABLE OF CONTENTS}

Page

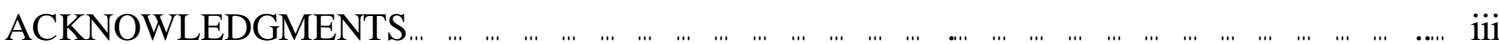

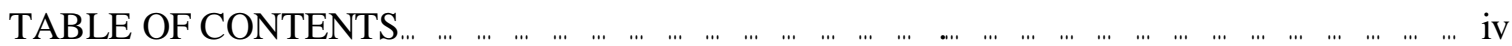

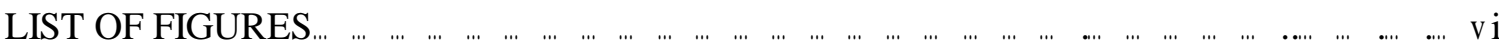

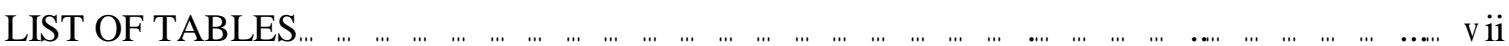

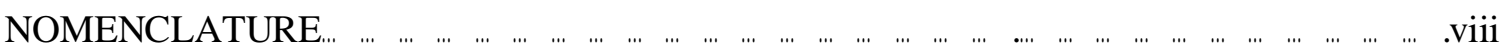

CHAPTER 1. INTRODUCTION........................................................1

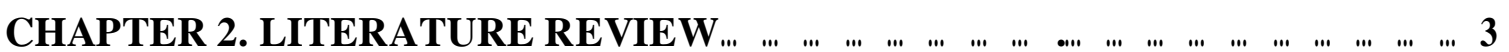

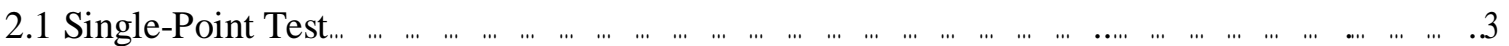

2.2 Unsteady-State Radial Gas Flow Equation .................................................

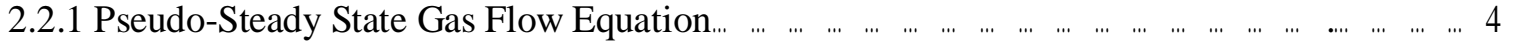

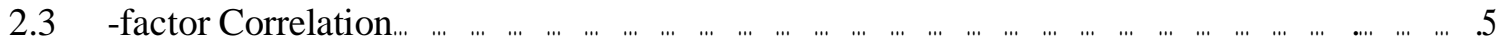

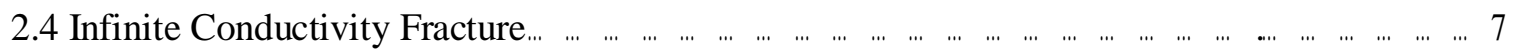

2.5 Effect of non-Darcy on Fractured Well.....................................................

2.5.1 Linear Flow Regime in Infinite Conductivity Fractures.................................. 9

2.5.2 Linear and Bilinear Flow Regime in Finite-Conductivity Fractures......................10

CHAPTER 3. METHODOL OGY ......................................................12

3.1 Determine Skin Factor from Single-Point Test using Transient Radial Flow Case............13

3.2 Impact of Formation Permeability on the Determination of the Skin Factor on Transient

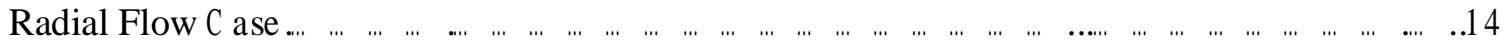

3.3 Determine Skin Factor from Single-Point Test using Linear Flow Case.....................15

3.4 Impact of Formation Permeability on the Determination of the Skin Factor on Linear Flow

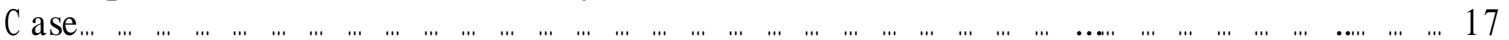

3.5 Impact of Time on Flow Rate for Transient Radial and Linear Flow..........................18

CHAPTER 4. RESULTS AND DISCUSSIONS..................................... 19

4.1 Impact of Formation Permeability on Skin Factor for Transient Radial Flow..................19

4.2 Impact of Formation Permeability on Skin Factor for Linear Flow.........................20

4.3 Flow Rate versus Time using Linear and Radial Flow......................................

CHAPTER 5. CONCLUSIONS AND RECOMMENDATIONS......................24

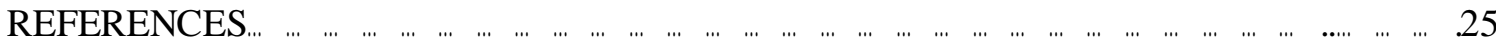

Appendix A. Determining Skin Factor from a Single-Point Test for Transient Radial Flow Solution Results........................................................................29

Appendix B. Determining Flow Rate using Transient Radial Flow Solution Results..............37

Appendix C. Determining Skin Factor and Flow Rate using Linear Flow Solution

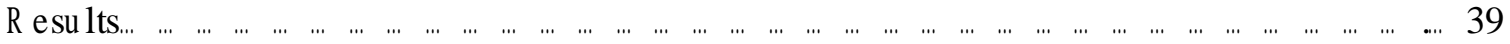


Appendix D. Flow Rate versus Time (Linear Darcy, Linear non-Darcy and Radial non-

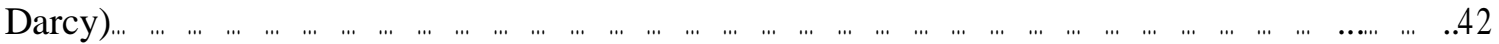

Appendix E. Impact of Formation Permeability to Determine Skin Factor on Transient Radial Flow Solution Results...............................................................49

Appendix F. Impact of Formation Permeability to Determine Skin Factor on Linear Flow

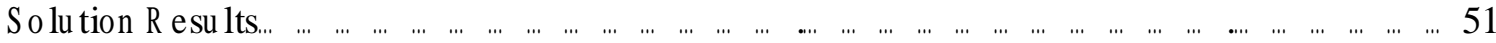




\section{LIST OF FIGURES}

Page

Figure 2.1: Linear Flow Regime...........................................................

Figure 2.2: Radial Flow Regime.......................................................

Figure 4.1: Skin Factor vs. Permeability (Transient Radial Flow) .............................19

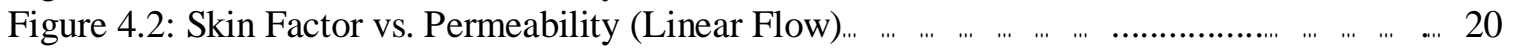

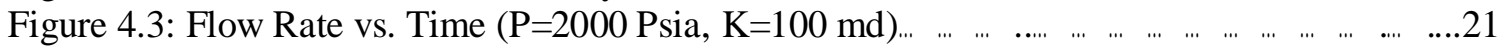

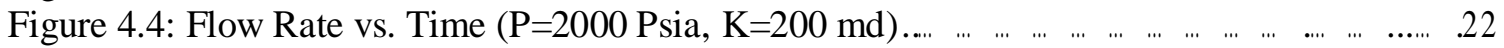

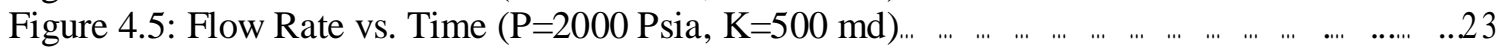

Figure A.1: z factor, Viscosity, and Compressibility Calculation Program.....................30

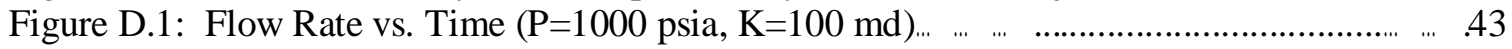

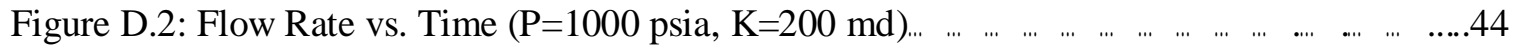

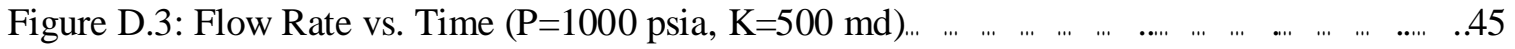

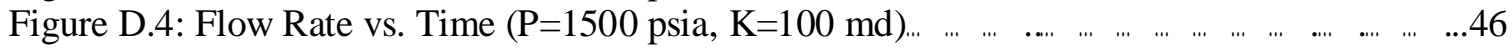

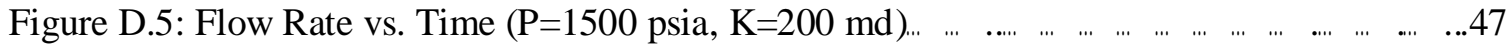

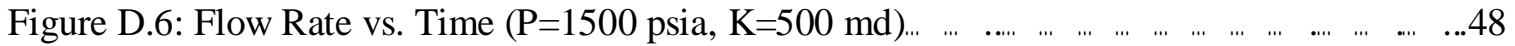




\section{LIST OF TABLES}

Page

Table 1: Constant a, b for Cooke's Correlation...................................................6

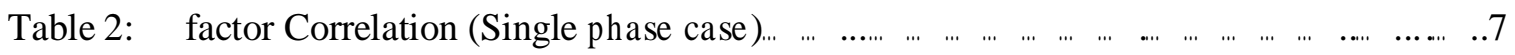

Table 3: Parameters used throughout this study............................................... 12

Table A.1: z factor, Viscosity, Compressibility Results..................................... 31

Table A.2: Pseudo-Pressure Calculation using the $\mathrm{z}$ factor, Viscosity, Compressibility Values

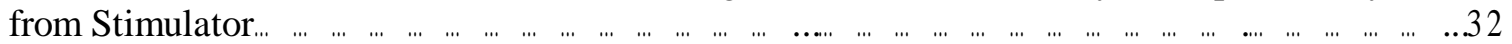

Table A.3: Non-Darcy Turbulence Coefficient, Apparent Skin Factor and Flowing Bottomhole

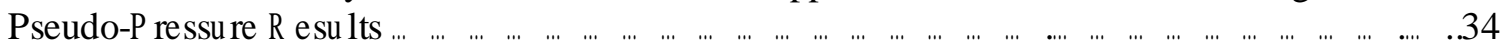

Table A.4: Flowing Bottomhole Pressure Results (Time $=49.99$ hrs) ................................35

Table A.5: Skin Factor Results........................................................... 36

Table B.1: Flow Rates using Pressure Transient Solution Results $\left(\mathrm{P}_{\mathrm{r}}=1500\right.$ psia and $\mathrm{t}=49.99$

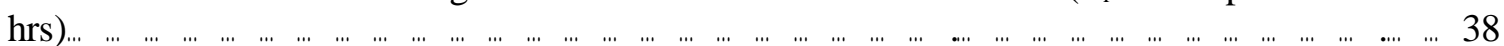

Table C.1: Skin Factors and Flow Rates Using Linear Flow Equation under non-Darcy Results

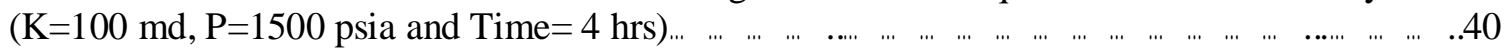

Table C.2: Skin Factors and Flow Rates Using Linear Flow Equation under Darcy Flow Results

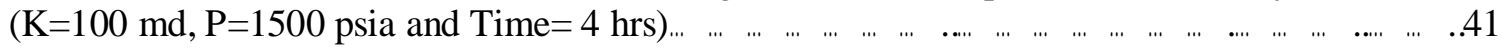

Table E.1: Impact of Permeability on Skin Factor Results (Radial Flow) .....................50

Table F.1: Impact of Permeability on Skin Factor Results (Linear Flow) ......................52 


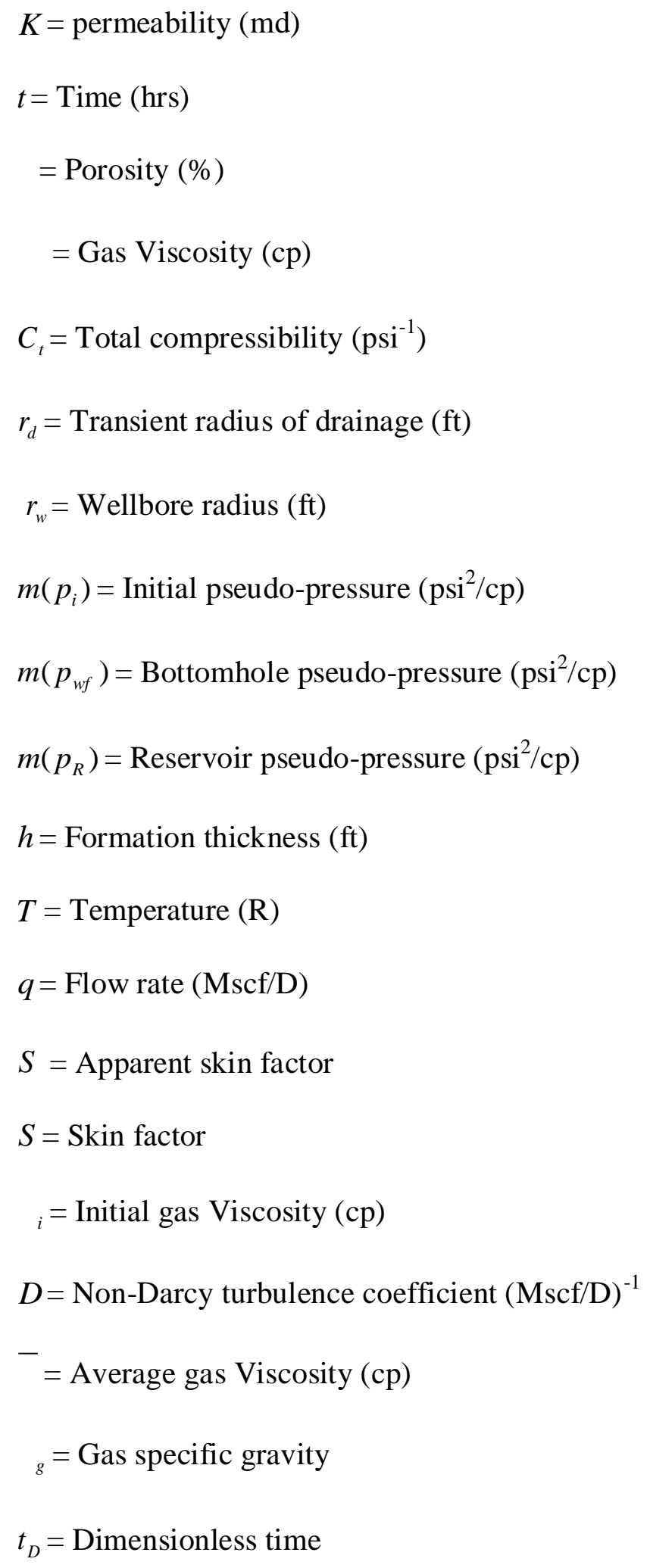




$$
\begin{aligned}
& \mathrm{P}=\text { Pressure }(\text { Psia }) \\
& \mathrm{z}=\text { Gas compressibility factor } \\
& \text { S } \quad S_{f}=S_{d}=\text { Damaged skin } \\
& D_{f}=\text { Non-Darcy flow factor for fractured wells } \\
& D_{w}=\text { Non-Darcy flow factor for nonfractured wells } \\
& =\text { Factor } \\
& =\text { Coefficient of internal resistance } \\
& =\text { Density }\left(\mathrm{lbm} / \mathrm{ft}^{3}\right) \\
& L_{f}=\text { Fracture length }(\mathrm{ft}) \\
& r_{e}=\text { Radius of outer boundary }(\mathrm{ft}) \\
& \mathrm{L}_{\mathrm{fD}}=\text { Dimensionless fracture half-length }\left(=\mathrm{L}_{\mathrm{f}} / \mathrm{r}_{\mathrm{e}}\right)
\end{aligned}
$$




\section{CHAPTER 1}

\section{INTRODUCTION}

Single-point test should be conducted generally after a four-point test. The test must be conducted for a minimum flow time of 48 hours but not more than 72 hours. One would use single-point test results to investigate if the well is damaged or stimulated. Some period of time (one year) after a four-point test had been conducted, one could use a single-point test to investigate well conditions (either damage or stimulation). The fourpoint test results can be plotted as $p^{2}$ versus $q$ to establish baseline performance. The single-point test result can then be plotted on the same graph. Therefore it is possible to find out if the well performance has been altered. Single-point flow data are nearly always available on gas wells therefore this makes single-point test to be appealing compare to the build-up test.

The typical gas storage reservoirs are in general high permeability clastics or carbonates and these reservoirs are depleted formations that contain natural gas. Natural gas is mostly stored in porous reservoirs. Natural gas can be either injected into the underground storage reservoirs or removed from the underground storage reservoirs depending on the market demand. Natural gas is injected into the underground storage reservoirs when the pipeline capacity exceed the market demand during the summer however this gas is withdrawn from the underground storage reservoirs when the market demand exceed the pipeline capacity. It is also possible for gas to move from the storage which can be results of many factors such as permeability of the rock, pressure gradient, faults, fractures, operating conditions, integrity of caprock and others (Tek, 1987). 
Previous studies have discussed formation permeability determination using single-point test data. In these studies, the value of skin factor had to be estimated to calculate formation permeability from single-point test. Estimating skin factor is the biggest limitation to single-point method and usually the main source of error.

The present study aims to determine skin factor from single-point test for two cases including transient radial and linear flow. In the present work, the permeability is assumed to be available and the skin factor is determined from single point-test data. The impact of formation permeability on the estimated skin factor has been also studied for cases including transient radial and linear flow. 


\section{CHAPTER 2}

\section{LITERATURE REVIEW}

\subsection{Single-Point Test}

Single-point test on a well will be required in the following two cases first for calculating AOF and flow coefficient, C. Secondly, for calculating skin factor, S, if non-Darcy flow coefficient, D or exponent $\mathrm{n}$ are already obtained from the previous test (Chaudry, 2003). Accordingly the non-Darcy flow coefficient can be estimated from different tests data. Single-point test is neither expensive nor time-consuming compare to other tests. Well produces only at one rate in the single-point test. However, well produces at different rates (Typically four) in multi-point test. Build-up and drawdown tests are more accurate than single-point test however one may use single-point test in the absence of drawdown and build-up data. The accuracy of single-point test will be associated with estimating a proper value of permeability to determine skin factor from single-point test data (Lee et al, 1984).

The transient radius of drainage $r_{d}$ is similar to the radius of investigation and it is given by the following equation:

$$
r_{d}\left(\frac{k t}{376 c_{t}}\right)^{\frac{1}{2}}
$$

The pseudo steady-state flow equation shows that well can be flowing at pseudo steadystate condition with a drainage radius that is continuously moving outward. The pseudosteady state is given by the following equation (Houpeurt, 1959):

$$
\frac{k h}{1422 q_{g}^{\top}}\left[m\left(p_{i}\right) \quad m\left(p_{w f}\right)\right] \quad \ln \left(\frac{r_{d}}{r_{w}}\right) \quad 0.75 \quad S
$$




\subsection{Unsteady-State R adial Gas F low E quation}

Unsteady-state radial gas flow solution is usually used for pressure drawdown analysis with a constant-rate gas production. Radial unsteady-state gas flow is given by the following equation (Houpeurt, 1959):

$$
m\left(P_{i}\right) \quad m\left(P_{w f}\right) \quad \frac{1637 q T}{k h}\left[\log t \quad \log \frac{k}{{ }_{i} c_{t i} r_{w}^{2}} \quad 3.23 \quad 0.869 S\right. \text { ] }
$$

One can notice that pressure responses as function of time when unsteady-state radial gas flow equation is used.

Muskut (1937), Katz (1959), and Wattenbarger and Ramey (1968), all describe nonDarcy flow close to the wellbore depend on skin. Total skin factor is given by the following equation:

$$
S^{\prime} \quad S \quad D q_{g}
$$

The non-Darcy turbulence coefficient is given by the following equation (Katz et al 1959):

$$
\text { D } \frac{2.2210^{15}{ }_{\mathrm{g}} \mathrm{k}}{\mathrm{hr}_{\mathrm{w}}}
$$

\subsubsection{Pseudo-Steady State Gas F low E quation}

Pseudo-steady state constant rate solution is usually used for the deliverability test analysis and is given by the following equation (Houpeurt, 1959):

$$
m\left(\overline{p_{R}}\right) \quad m\left(p_{w f}\right) \quad \frac{1422 T q_{s c}}{k h}\left[\ln \left(\frac{0.472 r_{e}}{r_{w}}\right) \quad S \quad D q_{s c}\right]
$$




\section{3 -factor Correlation}

Darcy's law describes the linear proportionality developed by Henry Darcy in 1856 as shown by the following equation:

$$
\frac{P}{L} \quad \frac{V}{K}
$$

Darcy's law is however inad equate for describing high flow of gas through porous media as identified for more than one century. Forchheimer proposed a second order equation as shown by the following equation :

$$
\frac{P}{L} \frac{V}{K_{d}} \quad V^{2}
$$

Forchheimer equation introduces a pressure drop term due to high flow velocities.

\section{* -factor Correlation for fractures and non-fractures}

Janicek and Katz (1955) were the first to develop a correlation for (The non-Darcy coefficient) as a function of permeability and porosity of the porous medium. A correlation was proposed by Tek et al (1962) after analyzing both Janicek and Katz data. This correlation is given by the following equation:

$$
\frac{5.5 \quad 10^{9}}{k^{5 / 4} 3 / 4}
$$

The non-Darcy flow effect for several fluids in different sizes of fracture propping agents at various temperature was considered by Cooke (1973). This correlation is given by the following equation:

$$
\frac{b}{k^{a}}
$$


Depending on propped type, the constant values of Cooke's correlation are shown in table below:

\section{Table 1: Constant a, b for Cooke's Correlation}

\begin{tabular}{|c|c|c|}
\hline Sand size & $\mathrm{a}$ & $\mathrm{b}$ \\
\hline $8-12$ mesh & 1.24 & 2.32 \\
\hline $10-20$ mesh & 1.34 & 2.63 \\
\hline $20-40$ mesh & 1.54 & 2.65 \\
\hline $40-60$ mesh & 1.6 & 1.1 \\
\hline
\end{tabular}

Cooke's correlation was only used for single-phase flow. Regarding to Cooke's conclusion, it is very important to consider the non-Darcy effects in designing fracture treatment for gas reservoirs. Cooke's correlation is an application that was derived for fracture system. Another correlation for gas flow in porous media was developed by Geertsma (1974). This correlation is given by the following equation:

$$
\frac{0.005}{\mathrm{k}^{0.5 \quad 0.5}}
$$

Geertsma (1974) also developed a correlation for for formation with an immobile liquid saturation. This correlation is given by the following equation:

$$
\frac{0.005}{\mathrm{k}^{0.5} 0.5}\left(\frac{1}{\left(1 \mathrm{~S}_{\mathrm{w}}\right)^{5.5} \mathrm{k}_{\mathrm{re}}^{0.5}}\right)
$$

New correlation for factor at both mobile and immobile liquid saturation was afterward offered by Frederick and Graves.

\section{* -factor C orrelation for Single-Phase C ase}

There are a number of correlations for predicting and permeability is the key parameter for all these correlations. Some of these correlations are listed in the table below (Li et al, 2001): 


\section{Table 2: Factor C orrelation (Single-Phase C ase)}

\begin{tabular}{|c|c|c|}
\hline Author name & Equation & Unit \\
\hline Thauvin and Mohant (1998) & $1.75150^{1 / 2}\left(10^{8} \mathrm{~K}\right)^{1 / 2}$ & $\mathrm{k}, \mathrm{d}$, and $\beta, 1 / \mathrm{cm}$ \\
\hline Janicek and Katz (1955) & $\begin{array}{lllll}1.82 & 10^{8} \mathrm{~K} & 5 / 4 & 3 / 4 \\
\end{array}$ & $\mathrm{k}, \mathrm{md}$, and $\beta, 1 / \mathrm{cm}$ \\
\hline Pascal et al. (1980) & $\frac{4.81 \mathrm{O}^{12}}{\mathrm{k}^{1.176}}$ & $\mathrm{k}, \mathrm{md}$, and $\beta, 1 / \mathrm{m}$ \\
\hline Jones (1987) & $\frac{6.1510^{10}}{k^{1.55}}$ & $\mathrm{k}, \mathrm{md}$, and $\beta, 1 / \mathrm{ft}$ \\
\hline Coles and Hartman (1998) & $\begin{array}{lll}1.07 & 10^{12} & 0.449 \\
& k^{1.88} & \end{array}$ & $\mathrm{k}, \mathrm{md}$, and $\beta, 1 / \mathrm{ft}$ \\
\hline Coles and Hartman (1998) & $\begin{array}{lll}2.49 & 10^{11} & 0.537 \\
k^{1.79} & \end{array}$ & $\mathrm{k}, \mathrm{md}$, and $\beta, 1 / \mathrm{ft}$ \\
\hline Li et al. (1995) & $\frac{11500}{K}$ & $\mathrm{k}, \mathrm{d}$, and $\beta, 1 / \mathrm{cm}$ \\
\hline
\end{tabular}

Table above for predicting is only for single-phase condition and these equations can not be used for multi-phase flow. Coles and Hartman (1998) proposed two methods, same porosity and simultaneous, to calculate as shown in the table above.

\subsection{Infinite C onductivity Fracture}

There are three types of fracture behavior that can be observed in a well test: (1) Low (Finite) conductivity fracture (2) high (Infinite) conductivity fracture (3) uniform flux fracture. In infinite conductivity fracture linear flow starts first, then followed by radial flow.

Infinite conductivity fracture has different flow regimes, which are shown by the following figures. 


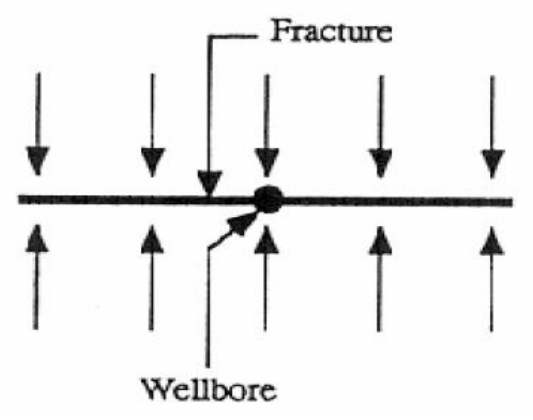

Figure 2.1: Linear Flow R egime

Figure 2.1 shows flow is occurring toward fracture. Pressure drop inside the fracture during production is zero in infinite-conductivity fracture.

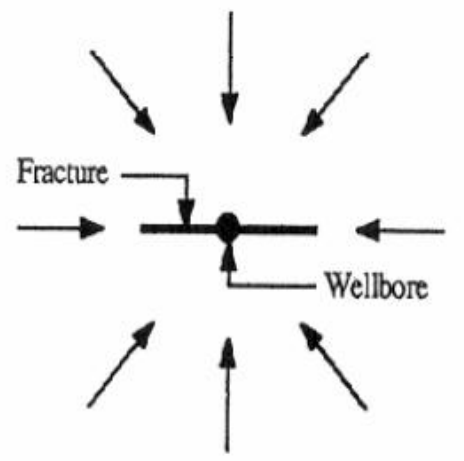

Figure 2.2: R adial Flow R egime

Figure 2.2 shows flow is occurring toward fracture. Radial flow regime will occur after linear flow in infinite conductivity fracture.

\subsection{E ffect of non-D arcy on Fractured Well}

Non-Darcy flow will play an extremely significant role for pressure drop in the hydraulically fractured gas wells, where high velocity occurs in the fracture. This will result in pressure distribution in the entire reservoir following pressure distribution in the 
fracture. Non-Darcy flow would be less important in the formation than inside of the fracture (Alvarez et al 2002). Hydraulic fractures will reduce the effect of non-Darcy flow (Hagoort, 2002). Millheim and Cichowicz (1968) were first to observe the effect of non-Darcy flow on vertically fractured well. Holditch and Morse (1976) also discussed the effect of non-Darcy flow in both reservoir and fracture system by using numerical models.

\subsubsection{Linear Flow R egime in Infinite C onductivity Fractures}

The following technique is based on the analytical expressions of linear flow regime in infinite conductivity fractures (Hagoort, 2002). Non-Darcy flow factor, $D_{f}$ for a fractured well is defined by following equation:

$$
D_{f} \frac{k}{2 h L_{f}}
$$

For comparison, Non-Darcy flow factor, $D_{w}$ for non-fractured well can be defined by following equation:

$$
D_{w} \frac{k}{2 h r_{w}}\left(1 \quad r_{w} / r_{e}\right)
$$

Except for fracture half-length, $L_{f}$ and , equation 13 is similar to the one that is used for radial flow. can be expressed as shown below (Hagoort, 2002):

$$
\frac{-}{2}\left(\frac{2 L_{f}}{r_{e}}\right) \quad \overline{2} \quad L_{f D}
$$

Fracture skin can also be calculated and is given by the following equation for infinite conductivity fracture: 


$$
S_{f} \ln \frac{2 r_{w}}{L_{f}}
$$

\subsubsection{L inear and Bilinear Flow R egime in Finite-C onductivity F ractures \\ L inear-Flow}

The following technique is based on the analytical expressions of linear regime in finite conductivity fractures (Gringarten et al, 1974). The dimensionless pseudo-pressure is defined, in field units, by:

$$
m_{D}\left(t_{d}\right) \frac{K h}{1422 q T} m\left(p_{i}\right) \quad m\left(p_{w f}\right)
$$

In the above equation, the dimensionless time, $t_{D}$ is defined by

$$
t_{D} \frac{2.63710^{4} k}{\left(c_{t}\right)_{i} L_{f}^{2}} t
$$

According to Camacho (1984), the pseudo-pressure responses of finite conductivity fractures during the reservoir's linear-flow period, could be expressed for Darcy and nonDarcy using equations below respectively:

$$
\begin{gathered}
\mathrm{m}_{\mathrm{wD}}(\text { Darcy }) \sqrt{\mathrm{t}_{\mathrm{D}}} \frac{\mathrm{a}}{\mathrm{C}_{\mathrm{fD}}} \\
\mathrm{m}_{\mathrm{wD}}\left(\text { non Darcy) } \sqrt{\mathrm{t}_{\mathrm{D}}} \frac{\mathrm{a}}{\mathrm{C}_{\mathrm{fD}, \mathrm{app}}}\right.
\end{gathered}
$$

$$
\begin{aligned}
& a=\pi / 3 \text { for } C_{f D} \\
& a=0.944 \text { for } C_{f D} \\
& a=0.902 \text { for } C_{f D} \quad 5
\end{aligned}
$$




\section{Bilinear-F low}

According to Cinco and Samaniego (1978), the pseudo-pressure responses of finite conductivity fractures during the reservoir's bilinear-flow period, could be expressed for Darcy using equation below:

$$
m_{w D}(D \text { arcy }) \quad \frac{}{(5 / 4) \sqrt{2 C_{f D}}} t_{D}^{1 / 4}
$$

According to Guppy et al. (1982), the pseudo-pressure responses of finite conductivity fractures during the reservoir's bilinear-flow period, could be expressed for non-Darcy using equation below:

$$
\mathrm{m}_{\mathrm{wD}}\left(\text { non } \quad \text { arcy) } \frac{}{(5 / 4) \sqrt{2 C_{\mathrm{fD}, \text { app }}}} \mathrm{t}_{\mathrm{D}}^{1 / 4}\right.
$$




\section{CHAPTER 3}

\section{METHODOLOGY}

The objective of this study was to analyze single-point test to determine skin factor. To achieve the objective, the following 3 steps were employed:

1. A methodology to determine skin factor from single-point test data, using transient radial and linear flow solutions.

2. Study the impact of formation permeability on the determination of the skin factor for both cases.

3. Impact of time on flow rate using linear and radial flow cases under study.

Table 3 shows the parameters that were used throughout this study.

Table 3: Parameters used, throughout this study

\begin{tabular}{|c|c|}
\hline $\mathrm{q}(\mathrm{Mscf} / \mathrm{D})$ & 150450 \\
\hline $\mathrm{r}_{\mathrm{w}}(\mathrm{ft})$ & 0.33 \\
\hline $\mathrm{T}\left({ }^{\circ} \mathrm{F}\right)$ & 80 \\
\hline $\mathrm{h}(\mathrm{ft})$ & 100 \\
\hline $\mathrm{k}(\mathrm{md})$ & 100 \\
\hline$\varphi(\%)$ & 20 \\
\hline Gas Gravity & 0.6 \\
\hline
\end{tabular}




\subsection{Determine Skin Factor from Single-Point T est using Transient $R$ adial Flow $C$ ase}

Parameters such as gas viscosity, compressibility and z factor were calculated at reservoir pressure of 1000 psia, 1500 psia and 2000 psia respectively from fluid properties and reservoir program. In this research, the following correlation was used, which is very similar to Jones (1987) to determine -factor and is given by the following equation:

$$
\frac{2.3310^{10}}{k^{1.2}}
$$

Where

$\mathrm{k}=$ Permeability (md)

$=1 / \mathrm{ft}$

The non-Darcy turbulence coefficient, $\mathrm{D}$ is determined and is given by the following equation:

$$
\text { D } \frac{5.1810^{5} g}{{ }_{w} h_{w} k^{0.2}}
$$

Total skin factor (Using eq.4) is afterward determined. Next the flowing bottomhole pseudo-pressure is determined using unsteady-state radial gas flow that is given by the following equation:

$$
m\left(P_{w f}\right) \quad m\left(P_{R}\right) \quad\left[\frac{1637 q T}{k h}\left\{\log t \quad \log \frac{k}{{ }_{i} C_{t i} r_{w}^{2}} 3.23 \quad 0.869 S\right\}\right]
$$

Therefore skin factor can be determined from single-point test data. Initially transient radius of drainage (Using eq.1) is determined. Then apparent skin factor is determined using pseudo-steady state flow and is given by the following equation:

$$
S^{\prime} \frac{k h}{1422 q_{g}^{\top}}\left[m\left(p_{i}\right) \quad m\left(p_{w f}\right)\right] \quad \ln \left(\frac{r_{d}}{r_{w}}\right) \quad 0.75
$$


Finally, skin factor is determined for transient radial flow using equation below (Refer to Appendix A):

$$
S \quad S^{\prime} \quad D q_{g}
$$

In this section, our first step is to calculate flowing bottomhole pressure using constant flow rate. Formation permeability is assumed to be available to determine skin factor from single-point test data.

\subsection{I mpact of F or mation Permeability on the Deter mination of the Skin F actor on Transient Radial Flow C ase}

Flowing bottomhole pressure for reservoir pressure of 1000 psia, 1500 psia and 2000 psia is provided using equation $p^{2} \quad P_{R}^{2} \quad P_{w f}^{2} \quad 10^{6}$ where $\quad p^{2}$ is taken as $10^{6}$, as it is a common practice in gas storage. In addition well test is generally done taking $p^{2} \quad 10^{6}$. Flow rate is determined using radial unsteady-state flow equation (Using eq.3), after replacing apparent skin factor equation (Using eq.4) and the non-Darcy turbulence coefficient equation (Using eq.5). Therefore these expressions become:

$$
m\left(p_{i}\right) \quad m\left(p_{w f}\right) \quad \frac{1637 q T}{k h}\left[\log t \quad \log \frac{k}{{ }_{i} C_{t i} r_{w}^{2}} \quad 3.23 \quad 0.869 S \quad 0.869 \frac{5.18}{-h^{2} r_{w} k^{0.2}} \quad q\right](28)
$$

Quadratic equation is developed to determine flow rate for a given reservoir pressure on transient radial flow case (Refer to Appendix B).

\section{Where}

$$
\begin{aligned}
& \text { a } \frac{1637 T}{k h}[0.869 D] \frac{1422 T D}{k h} \\
& \text { b } \frac{1637 \mathrm{~T}}{\mathrm{kh}}\left[\log \mathrm{l} \quad \log \frac{\mathrm{k}}{{ }_{\mathrm{i}} \mathrm{C}_{\mathrm{ti}} \mathrm{r}_{\mathrm{w}}^{2}} \quad 3.23 \quad 0.869 \mathrm{~S}\right]
\end{aligned}
$$


c $m\left(p_{i}\right) \quad m\left(p_{w f}\right)$

First step is to study the impact of formation permeability to determine skin factor on transient radial flow case. We can calculate $a_{i}$ and $a_{\text {new }}$ from four-point test and singlepoint test respectively:

$$
\begin{aligned}
& a_{i} \frac{1637 T}{k h}\left[\log t \quad \log \frac{k}{{ }_{i} C_{t i} r_{w}^{2}} \quad 3.23 \quad 0.869 S_{i}\right] \text { (Four-point test) } \\
& a_{\text {new }} \frac{1637 \mathrm{~T}}{\mathrm{kh}}\left[\begin{array}{llll}
\log \mathrm{t} & \log \frac{\mathrm{k}}{{ }_{\mathrm{i}} \mathrm{C}_{\mathrm{ti}} \mathrm{r}_{\mathrm{w}}^{2}} \quad 3.23 \quad 0.869 \mathrm{~S}_{\text {new }}
\end{array}\right] \text { (Single-point test) } \\
& \frac{a_{i}}{a_{\text {new }}} \quad \frac{\frac{1637 T}{k h}[\log t}{\frac{k h T}{k h}\left[\begin{array}{lllll}
\log t & \log \frac{k}{{ }_{i} c_{t i} r_{w}^{2}} & 3.23 & 0.869 S_{i}
\end{array}\right]}
\end{aligned}
$$

The above equation is solved for $S_{\text {new }}$ once $a_{i}$ and $a_{\text {new }}$ are estimated from the procedure above. One needs to estimate permeability and skin factor in order to determine $a_{i}$ and $a_{\text {new }}($ Refer to Appendix E).

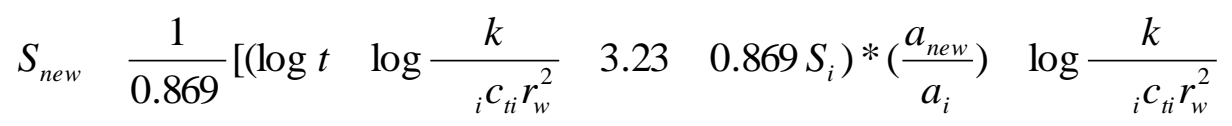

\subsection{Determine Skin Factor from Single-Point T est using L inear Flow C ase \\ Linear Flow non-Darcy Flow C ase}

In this section, the dimensionless pseudopressure, $m_{w D}$ for linear flow with non-Darcy effect in infinite-conductivity fractures is given by the following equation:

$$
m_{D}\left(\text { Non Darcy) } \sqrt{t_{d}}\left(\begin{array}{lll}
S & S_{f}
\end{array}\right) D_{f} q\right.
$$


Factor can be determined (Using eq.15). The non-Darcy flow factor, $D_{f}$ for a fracture well is also determined (Using eq.13). Fracture skin, $S_{f}$ is determined for infinite conductivity fracture (Using eq.16). Finally, the flow rate is determined using linear flow with non-Darcy effect and is shown by the following procedures:

$$
\begin{aligned}
& \frac{K h}{1422 q T} m\left(p_{i}\right) \quad m\left(p_{w f}\right) \quad \sqrt{t_{d}} \quad\left(\begin{array}{llll}
S & S_{f}
\end{array}\right) \quad D_{f} q \\
& \operatorname{Khm}\left(p_{i}\right) \quad m\left(p_{w f}\right) \quad 1422 q T \sqrt{t_{d}} \quad 1422 q T\left(\begin{array}{lll}
S & S_{f}
\end{array}\right) \quad 1422 q^{2} T D_{f}
\end{aligned}
$$

Then a quadratic equation was developed to determine flow rate for a given reservoir pressure for linear flow case (Refer to table C.1).

\section{Where}

$$
\begin{array}{lll}
\text { a } & 1422 T D_{f} \\
\text { b } & 1422 T \sqrt{t_{d}} & 1422 T\left(\begin{array}{ll}
S & S_{f}
\end{array}\right) \\
\text { c } & K h\left[m\left(p_{i}\right)\right. & \left.m\left(p_{w f}\right)\right]
\end{array}
$$

Finally a methodology was developed to determine skin factor from single-point test data for linear flow case.

\section{Linear Flow Darcy Flow C ase}

The dimensionless pseudopressure equation for gas flow in infinite conductivity fracture is determined similar to Camacho equation (Using eq.19). Therefore pseudopressure is obtained by the following equation:

$$
m_{w D}\left(\text { Darcy) } \sqrt{t_{D}}\right.
$$

Flow rate for linear flow of infinite conductivity fracture is determined using the following procedures (Refer to table C.2): 


$$
\begin{gathered}
\frac{k h}{1,422 q T}\left[m\left(p_{i}\right) \quad m\left(p_{w f}\right)\right] \quad \sqrt{t_{D}} \\
\frac{k h\left[m\left(p_{i}\right) \quad m\left(p_{w f}\right)\right]}{1,422 q T}\left(t_{D}\right)^{0.5} \\
q \frac{k h\left[m\left(p_{i}\right) m\left(p_{w f}\right)\right]}{1,422 T\left(t_{D}\right)^{0.5}}
\end{gathered}
$$

\subsection{I mpact of F ormation Permeability on the Deter mination of the Skin F actor on}

\section{L inear Flow Case}

Second step is to study the impact of formation permeability to determine skin factor on linear flow case (Refer to Appendix F). One can calculate $a_{i}$ and $a_{\text {new }}$ from four-point test and single-point test respectively.

$$
\begin{aligned}
& a_{i} \quad 1422 T \sqrt{t_{d}} \quad 1422 T\left(\begin{array}{ll}
S & S_{f}
\end{array}\right)_{i} \text { (Four-point test) } \\
& a_{\text {new }} \quad 1422 T \sqrt{t_{d}} \quad 1422 T\left(\begin{array}{ll}
S & S_{f}
\end{array}\right)_{\text {new }} \text { (Single-point test) } \\
& \frac{a_{i}}{a_{\text {new }}} \frac{1422 T \sqrt{t_{d}}}{1422 T \sqrt{t_{d}}} 1422 T\left(\begin{array}{ll}
S & S_{f}
\end{array}\right)_{i}
\end{aligned}
$$

The above equation is solved for $\left(S S_{f}\right)_{\text {new }}$ once $a_{i}$ and $a_{\text {new }}$ are calculated from procedure above. One needs to estimate permeability and fracture skin factor in order to calculate $a_{i}$ and $a_{\text {new }}$ (Refer to Appendix F).

$$
\left(\begin{array}{lll}
S & S_{f}
\end{array}\right)_{\text {new }} \frac{a_{\text {new }}\left[\sqrt{t_{d}}\left(\begin{array}{ll}
S & S_{f}
\end{array}\right)_{i}\right.}{a_{i}} \sqrt{t_{d}}
$$




\subsection{I mpact of $T$ ime on Flow $R$ ate for Transient $R$ adial and $L$ inear Flow}

It is important to study if time has a significant impact on non-Darcy flow in different cases including transient radial and linear flow. It is possible to illustrate this impact once flow rate is determined in these cases, one can plot flow rate versus time to illustrate this impact (Refer to Appendix D). 


\section{CHAPTER 4}

\section{RESULTS AND DISCUSSION}

The objective of this research was to determine skin factor from single-point test data. The impact of formation permeability to determine skin factor was studied using different cases including transient radial and linear flow. Finally, the non-Darcy flow effects were also considered in all mentioned cases.

\subsection{Impact of Formation Permeability on Skin F actor for Transient R adial F low}

Figure 4.1 illustrates the impact of formation permeability to determine skin factor for transient radial flow case.

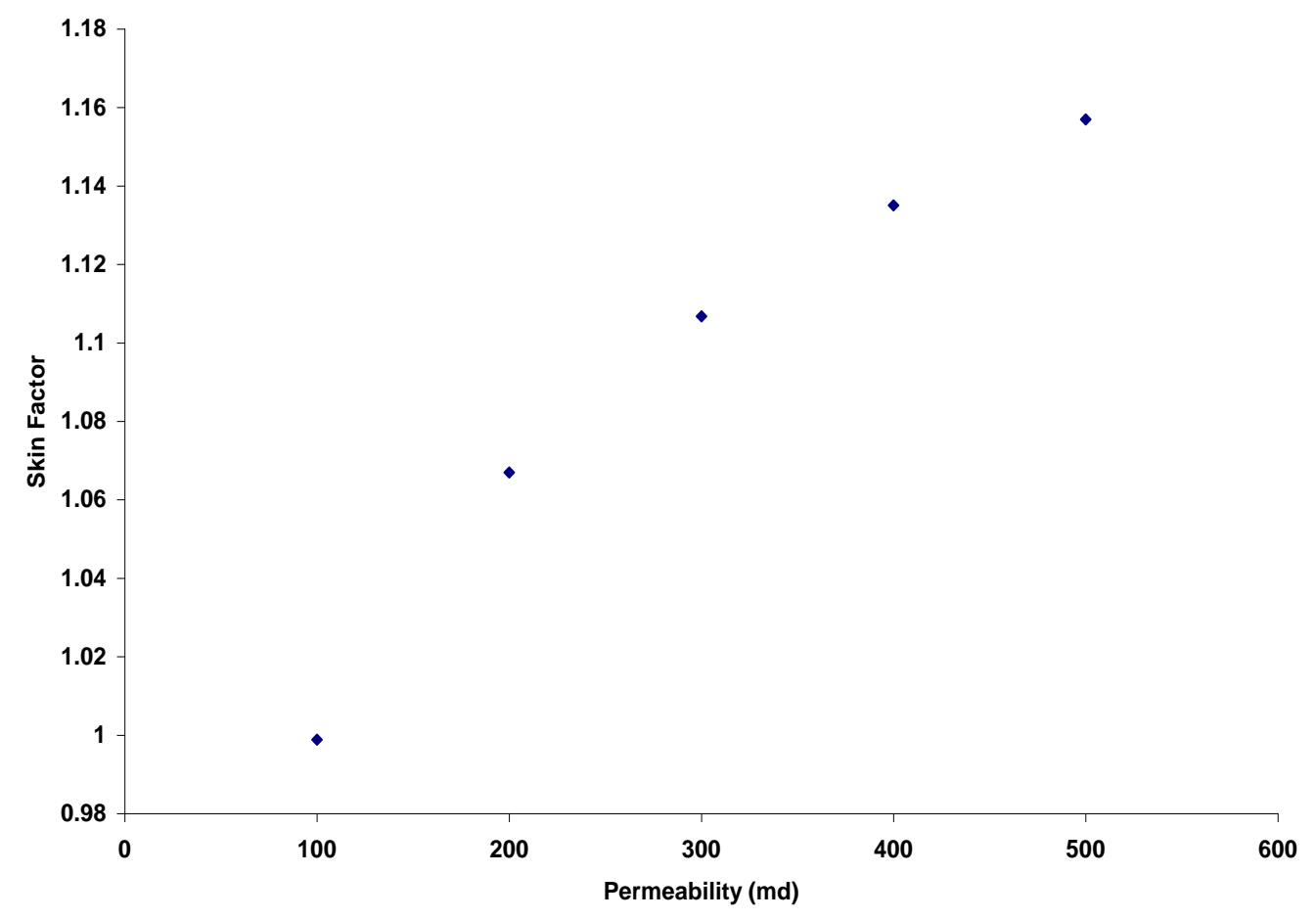

Figure 4.1: Skin F actor vs. Permeability (Transient R adial Flow) 
One can observe that formation permeability will not have a significant impact to determine skin factor for transient radial flow case.

\subsection{I mpact of Formation Permeability on Skin F actor for L inear Flow}

Figure 4.2 illustrates the impact of formation permeability to determine skin factor for linear flow case.

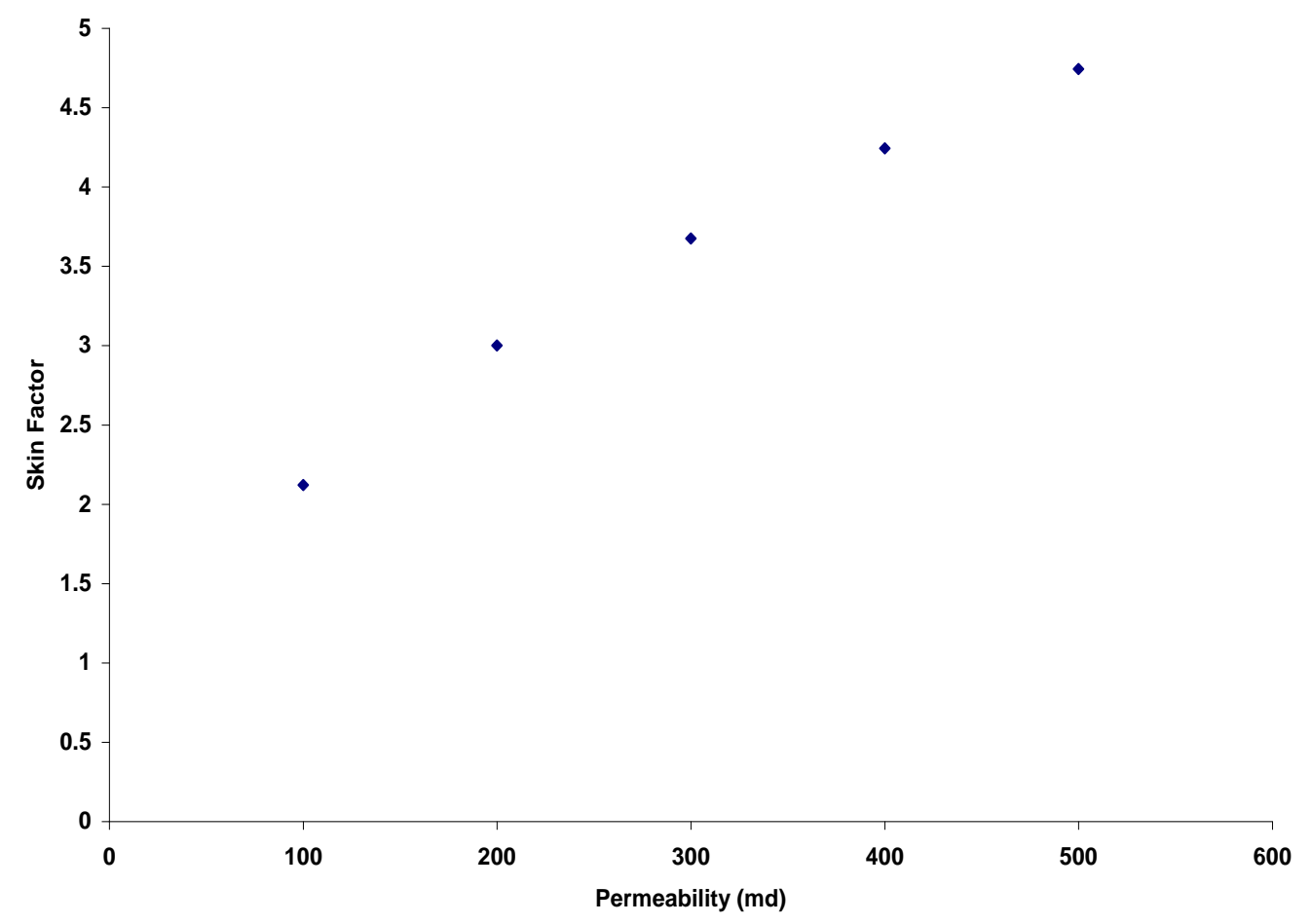

Figure 4.2: Skin F actor vs. Per meability (L inear Flow)

One can observe that formation permeability will have a significant impact to determine skin factor for linear flow case. 


\subsection{F low $R$ ate versus $T$ ime using $L$ inear and $R$ adial Flow}

Flow rate versus time for reservoir pressure of 2000 psia and permeability of $100 \mathrm{md}$ is shown below.

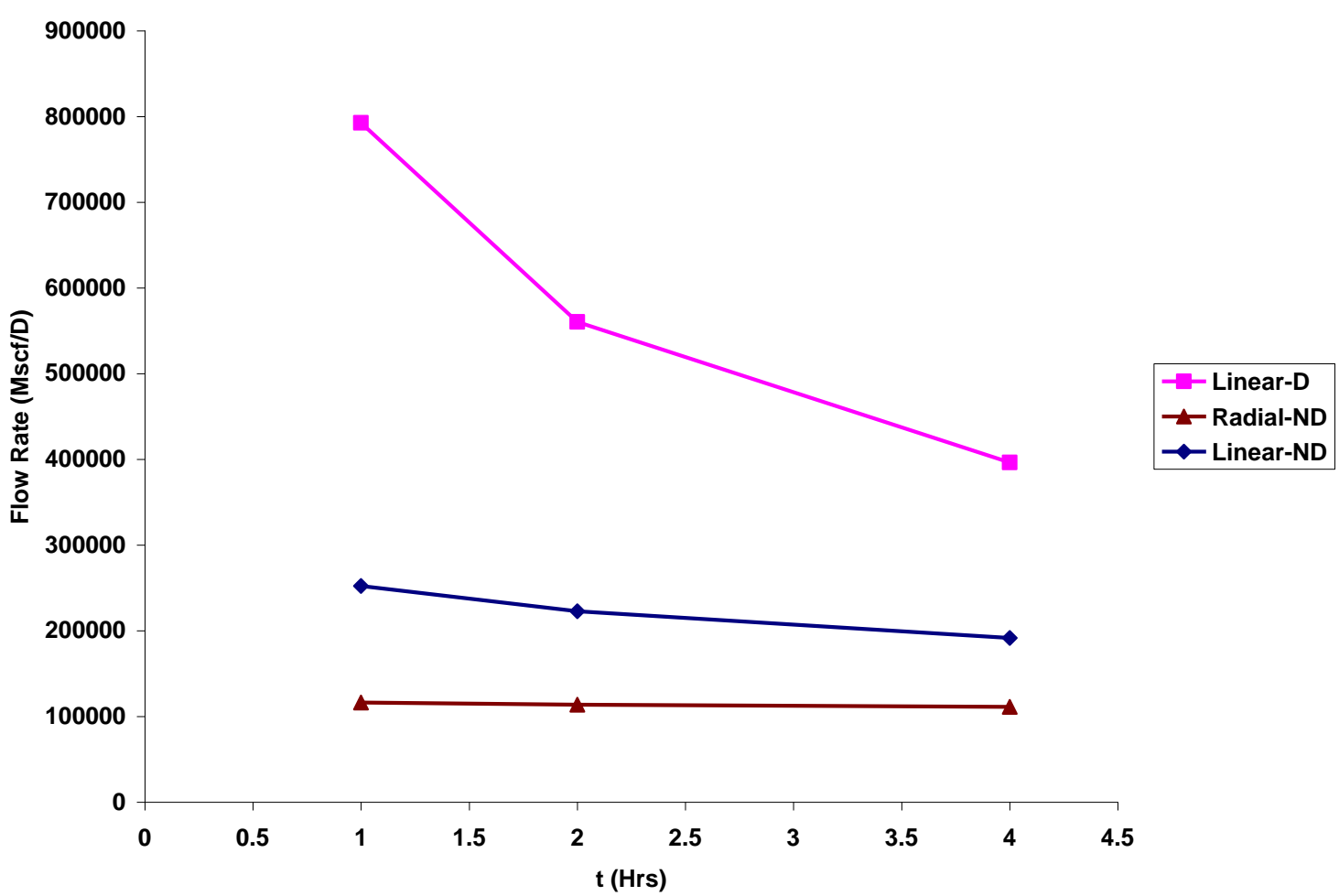

Figure 4.3: Flow Rate vs. Time ( $P=2000$ Psia, $K=100 \mathrm{md})$ 
Flow rate versus time for reservoir pressure of 2000 psia and permeability of $200 \mathrm{md}$ is shown below.

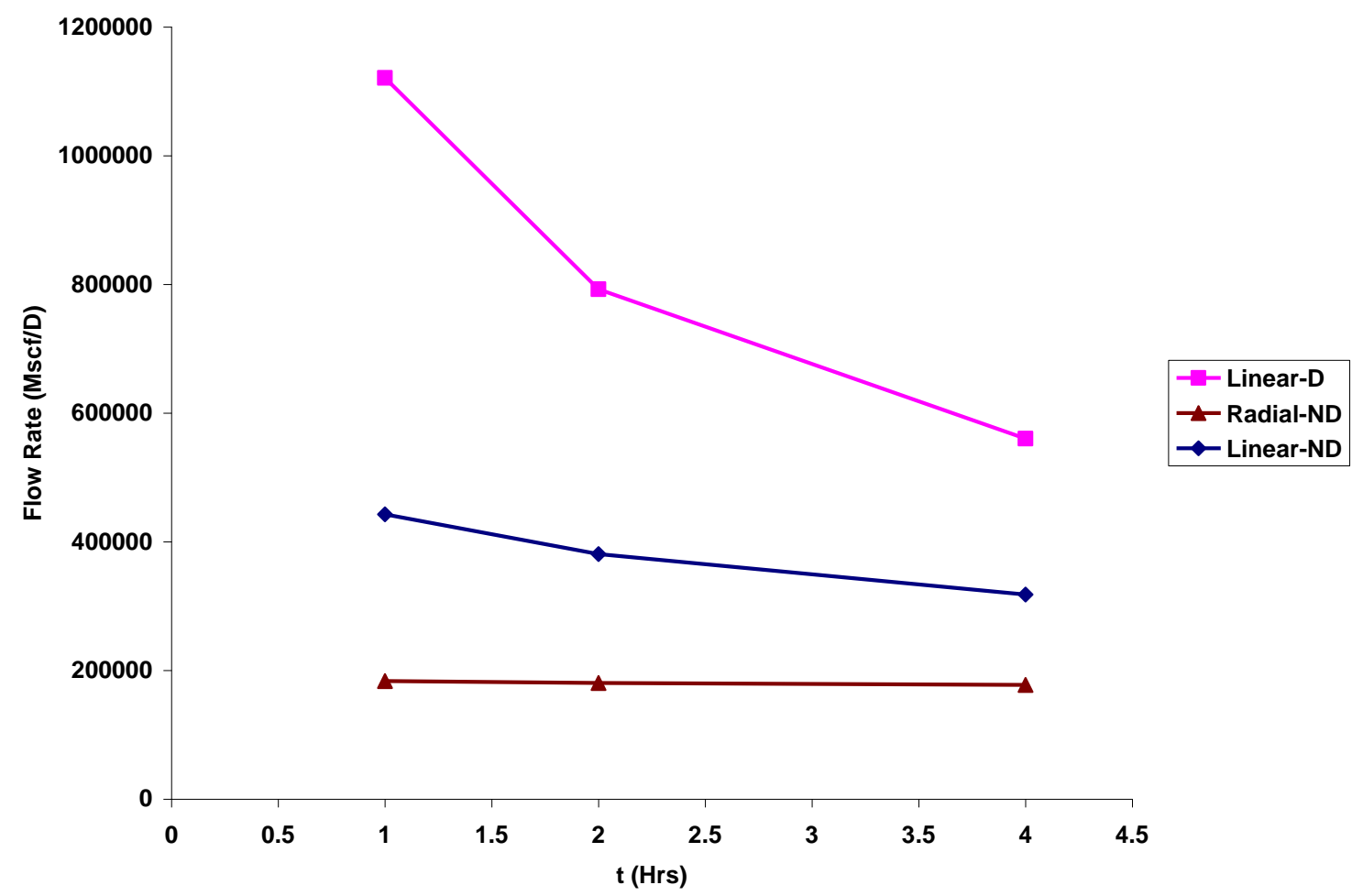

Figure 4.4: Flow $R$ ate vs. Time ( $P=2000$ Psia, $K=200$ md) 
Flow rate versus time for pressure of 2000 psia and permeability of $500 \mathrm{md}$ is shown below.

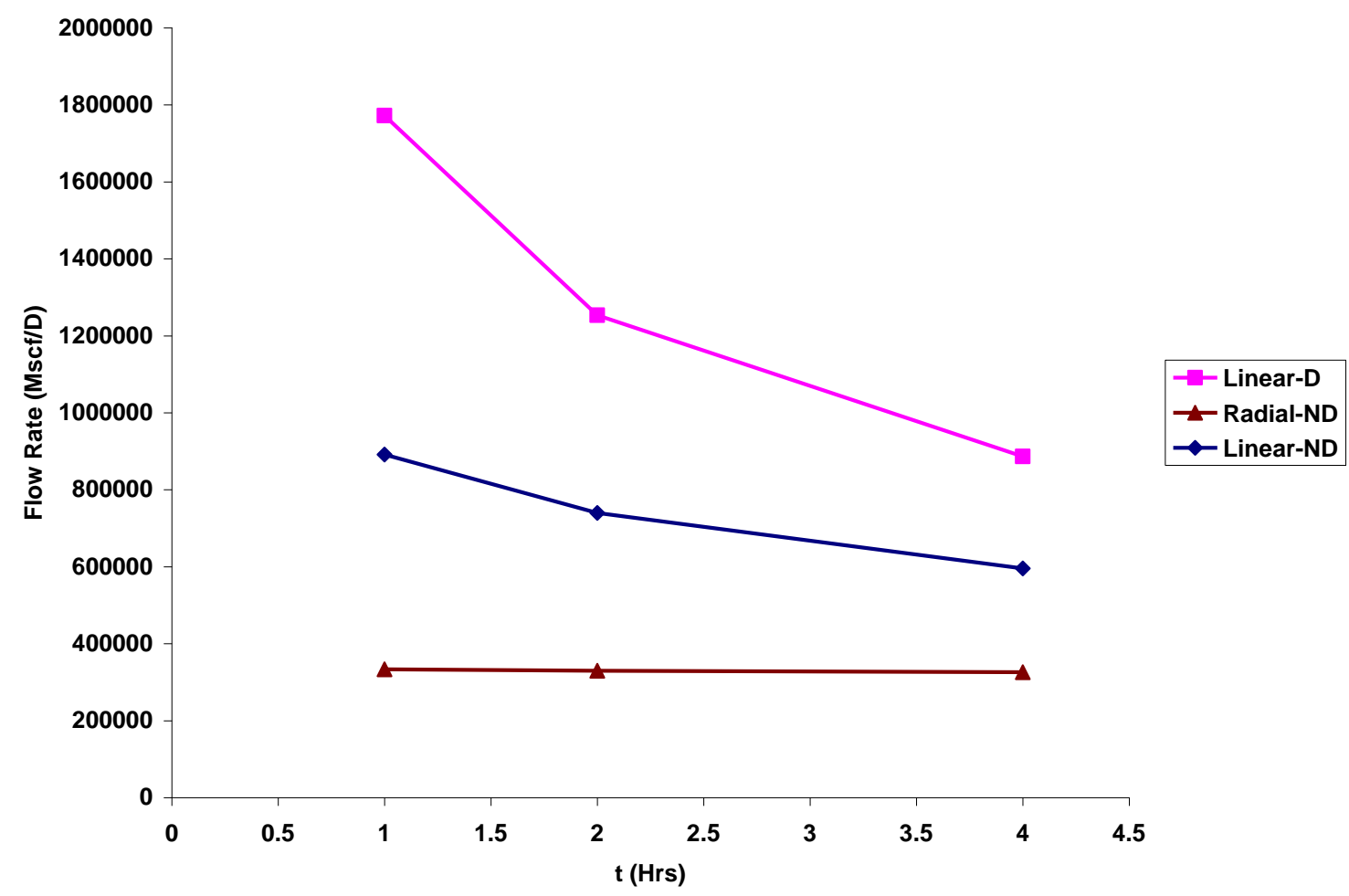

Figure 4.5: Flow $R$ ate vs. Time ( $P=2000$ Psia, $K=500 \mathrm{md})$

Figures 4.3, 4.4 and 4.5 all illustrate that non-Darcy does not show a considerable change between the time intervals of $t=1$ and $t=4$. This concludes that time does not have a significant impact on linear (Non-Darcy) and radial flow (Non-Darcy) solution. One also can conclude that time will have a significant impact on linear flow (Darcy) solution. 


\section{CHAPTER 5}

\section{CONCLUSIONS AND RECOMMENDATION}

The following conclusions were obtained based on the work done in this study:

1. A methodology to determine skin factor from single-point test data for transient radial and linear flow case were developed.

2. Formation permeability does not have a significant impact in determining skin factor using transient radial flow solution.

3. Formation permeability has a significant impact in determining skin factor using linear flow solution.

4. Time does not have a significant impact on linear and radial flow solution.

It is recommended to study, what causes formation permeability to have a significant impact on the determination of skin factor from single-point test data for linear flow case. 


\section{REFERENCES}

Alvarez. C.H., Holditch. S.A., Mcvay. D.A.: "Effect of non-Darcy flow on pressure transient analysis of hydraulically fractured gas wells” Paper SPE 77468 presented at the 2002 SPE Annual technical conference and exhibition, San Antonio, Texas, 29 September-2 October.

Aminian, K., PhD. PNGE 471 Natural Gas Engineering. Reservoir Property Computer Program. West Virginia University (2003).

Camacho-V., R. G.: Response of Wells Producing Commingled Reservoirs: Unequal Fracture Length, MS Thesis, The University of Tulsa, Tulsa, OK (1984)

Chaudhry, A. Gas well testing handbook. Amsterdam: Boston, 2003.

Cinco, H., Samaniego, F.: "Transient Pressure Analysis: Finite Conductivity Fracture Case Versus Damaged Fracture Case", paper SPE 10179 presented at the 6th SPE

Cinco-Ley, H., F. Samaniego-V, and N. Dominguez-A. (1978). “Transient Pressure Behavior for a Well with a Finite Conductivity Vertical Fracture,” Society of PetroleumEngineers Journal.

Coles, M.E., and Hartman, K.J.: "Non-Darcy Measurements in Dry Core and the Effect of Immobile Liquid," paper SPE 39977. 
Cooke, C.E., Jr.: "Conductivity of Fracture Proppants in Multiple Layers," JPT (1973), 1101-1107.

Forchheimer, P.: "Wasserbewegung durch Boden," ZVDI (1901) 45, 1781.

Frederick Jr., D.C. and Graves, R.M.: "New Correlations to Predict Non-Darcy Flow Coefficients at Immobile and Mobile Water Saturation," paper SPE 28451 presented at the 1994 SPE Annual Technical Conference and Exhibition, New Orleans, Sept. 25-28.

Geertsma, J.: "Estimating the Coefficient of Inertial Resistance in Fluid Flow through Porous Media," SPEJ (Oct. 1974) 445-450.

GRINGARTEN, A.C., RAMEY, H.J., JR., and RAGHAVAN, R. (1974). “Unsteadystate pressure distributions created by a well with a single infinite-conductivity vertical fracture”. SPEJ., Aug., 347-360

Guppy, K. H., Cinco-Ley, H., Ramey, Jr. H. J., and Sameniego V., F.: “Non-Darcy Flow in Wells with Finite-Conductivity Vertical Fractures” SPEJ (Oct. 1982) 681

Hagoort, J.: “Non-Darcy flow near hydraulically fracture well” SPE 80419 presented at the 2002, Jan 15-March 17. 
Holditch, S. A. and Morse, R. A.: "The Effects of Non-Darcy Flow on the Behavior of Hydraulically Fractured Gas Wells,” JPT (Oct. 1976) 1169

Houpeurt A., “On the flow of gases in porous media”, Revue de l'Institut Francais du petrole, XIV, (11),pp. 1468-1684, 1959.

Janicek, J.D., and Katz, D.L.: "Applications of Unsteady State Gas Flow Calculations," Proc., U. of Michigan Research Conference, June 20, 1955.

Jones, S.C.: "Using the Inertial Coefficient, to Characterize Heterogeneity in Reservoir Rock," paper SPE 16949 presented at the 1987 SPE Annual Technical Conference and Exhibition,

Katz, D. L., Cornell, D., Kobayashi, R., Poettmann, F. H., Vary, J. A., Elenbaas, J. R. and Weinaug, C. F.: Handbook of Natural Gas Engineering, McGraw-Hill Book Co. Inc., New York, 1959.

Lee. W.J., Kuo. T.B., Holditch. S.A., Mcvay. D.A., Holditch \& Assocs. S.A.: "Estimating formation permeability from single-point flow data” Paper SPE 12847 presented at the 1984 SPE/DOE/GRI unconventional gas recovery symposium, Pittsburgh, PA, 13-15 May. 
Li, D., Engler, T.: “Literature review on correlation of the non-Darcy coefficient” Paper SPE 70015 presented at the 2001 SPE permain basin oil and gas recovery conference, Texas, 15-16 May.

Millheim, K. K. and Cichowicz, L.: "Testing and Analyzing Low-Permeability Fractured Gas Wells,” JPT (Feb. 1968) 193.

Muskat, M.: The flow of homogeneous fluid through porous media, mcgraw-hill book co. Inc., New York City (1937).

Pascal H., Quillian, R.G., Kingston, J.: "Analysis of Vertical Fracture Length and NonDarcy Flow Coefficient Using Variable Rate Tests," paper SPE 9438 presented at the 1980 SPE Annual Technical Conference and Exhibition, Dallas, Sept. 21-24

Tek, M”.R., Coats, K.H., and Katz, D.L.: "The Effect of Turbulence on Flow of Natural Gas through Porous Media,"JPT (July 1962) 799-806.

Tek, M.R., Underground Storage of Natural Gas, Gulf Publishing, 1987

Thauvin . F., and Mohanty, K.K.: "Network modeling of non-Darcy flow through porous media,“ Transport in porous media (1998) 31, 19-37.

Wattenbarger, R. A. and Ramey, H. J., Jr.: "Gas Well Testing with Turbulence, Damage and Wellbore Storage", J. Pet. Tech. (August 1968) 877-887. 
APPE NDIX A-Determining Skin F actor from a Single-Point Test for T ransient R adial F low Solution R esults 
Figure A.1- z factor, Viscosity, and Compressibility C alculation Program (A minian, 2003).

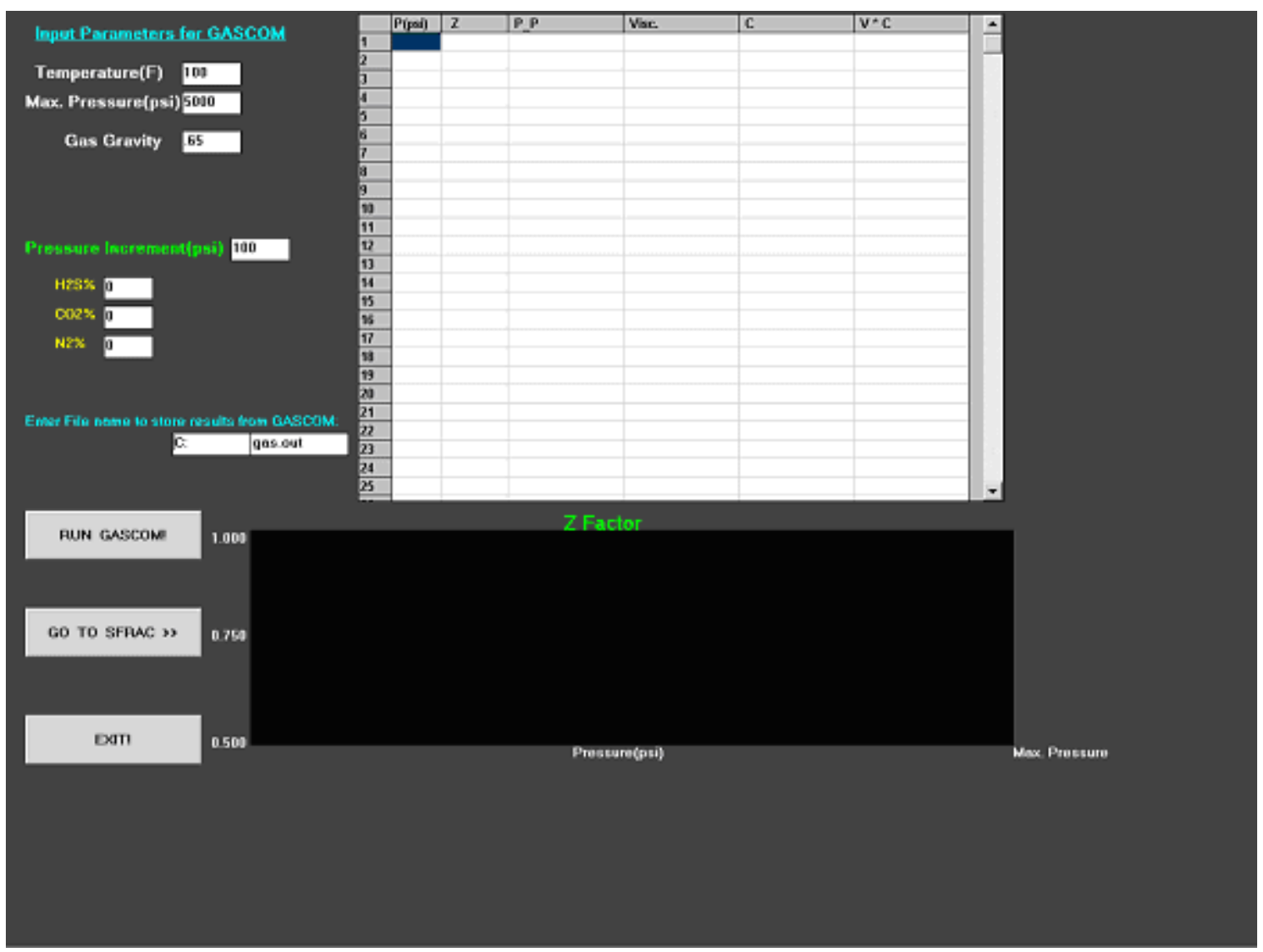


Table A.1- z factor, V iscosity, C ompressibility R esults

\begin{tabular}{|c|c|c|c|c|}
\multicolumn{1}{c}{} & program & program & program & program \\
\hline $\mathrm{t}, \mathrm{hrs}$ & $\mathrm{C}$ & $\mathrm{p}, \mathrm{psia}$ & $\mathrm{z}$ & $\mu, \mathrm{cp}$ \\
\hline 0 & $1.01 \mathrm{E}-02$ & 100 & 0.9888498 & $1.15 \mathrm{E}-02$ \\
\hline 0.09 & $5.11 \mathrm{E}-03$ & 200 & 0.9778506 & $1.16 \mathrm{E}-02$ \\
\hline 0.19 & $3.44 \mathrm{E}-03$ & 300 & 0.9670271 & $1.17 \mathrm{E}-02$ \\
\hline 0.29 & $2.61 \mathrm{E}-03$ & 400 & 0.9564064 & $1.19 \mathrm{E}-02$ \\
\hline 0.39 & $2.53 \mathrm{E}-03$ & 500 & 0.9460179 & $1.20 \mathrm{E}-02$ \\
\hline 0.49 & $1.77 \mathrm{E}-03$ & 600 & 0.9358935 & $1.22 \mathrm{E}-02$ \\
\hline 0.99 & $1.53 \mathrm{E}-03$ & 700 & 0.9260672 & $1.23 \mathrm{E}-02$ \\
\hline 1.99 & $1.35 \mathrm{E}-03$ & 800 & 0.9165752 & $1.25 \mathrm{E}-02$ \\
\hline 2.99 & $1.21 \mathrm{E}-03$ & 900 & 0.9074554 & $1.27 \mathrm{E}-02$ \\
\hline 4.99 & $1.09 \mathrm{E}-03$ & 1000 & 0.8987471 & $1.29 \mathrm{E}-02$ \\
\hline 5.99 & $9.99 \mathrm{E}-03$ & 1100 & 0.8904899 & $1.32 \mathrm{E}-02$ \\
\hline 6.99 & $9.18 \mathrm{E}-03$ & 1200 & 0.8827233 & $1.34 \mathrm{E}-02$ \\
\hline 9.99 & $8.49 \mathrm{E}-03$ & 1300 & 0.8754857 & 0.0136592 \\
\hline 11.99 & $7.88 \mathrm{E}-03$ & 1400 & 0.8688135 & $1.39 \mathrm{E}-02$ \\
\hline 13.99 & $7.33 \mathrm{E}-03$ & 1500 & 0.8627393 & $1.42 \mathrm{E}-02$ \\
\hline 15.99 & $6.85 \mathrm{E}-03$ & 1600 & 0.8572918 & $1.44 \mathrm{E}-02$ \\
\hline 17.99 & $6.41 \mathrm{E}-03$ & 1700 & 0.8524943 & 0.0147049 \\
\hline 19.99 & $6.00 \mathrm{E}-03$ & 1800 & 0.848364 & 0.0149649 \\
\hline 21.99 & $5.63 \mathrm{E}-03$ & 1900 & 0.8449116 & $1.52 \mathrm{E}-02$ \\
\hline 23.99 & $5.29 \mathrm{E}-03$ & 2000 & 0.8421413 & $1.55 \mathrm{E}-02$ \\
\hline 25.99 & $7.85 \mathrm{E}-03$ & 2100 & 0.8400503 & $1.58 \mathrm{E}-02$ \\
\hline 27.99 & $7.53 \mathrm{E}-03$ & 2200 & 0.83863 & $1.61 \mathrm{E}-02$ \\
\hline 29.99 & $4.40 \mathrm{E}-04$ & 2300 & 0.8378659 & 0.0164531 \\
\hline 31.99 & $4.10 \mathrm{E}-04$ & 2400 & 0.8377392 & $1.68 \mathrm{E}-02$ \\
\hline 33.99 & $3.91 \mathrm{E}-04$ & 2500 & 0.8382268 & $1.71 \mathrm{E}-02$ \\
\hline 35.99 & $3.68 \mathrm{E}-04$ & 2600 & 0.839303 & $1.74 \mathrm{E}-02$ \\
\hline 37.99 & $3.48 \mathrm{E}-04$ & 2700 & 0.8409398 & $1.78 \mathrm{E}-02$ \\
\hline 47.99 & $3.28 \mathrm{E}-04$ & 2800 & 0.8431082 & $1.81 \mathrm{E}-02$ \\
\hline 48.99 & $3.10 \mathrm{E}-04$ & 2900 & 0.8457785 & $1.85 \mathrm{E}-02$ \\
\hline 49.99 & $2.94 \mathrm{E}-04$ & 3000 & 0.8489212 & $1.88 \mathrm{E}-02$ \\
\hline & & & & \\
\hline
\end{tabular}


Table A.2- Pseudo-Pressure calculation using the $z$ factor, V iscosity, Compressibility Values from Stimulator

\begin{tabular}{|c|c|c|c|c|}
\hline $2 \mathrm{p} / \mu \mathrm{z}$ & $\mathrm{avg}(2 \mathrm{p} / \mu \mathrm{z})$ & $\mathrm{dP}$ & $\mathrm{avg}(2 \mathrm{p} / \mu \mathrm{z}) \mathrm{x} \mathrm{dp}$ & $\mathrm{m}\left(\mathrm{p}_{\mathrm{r}}\right),\left(\mathrm{psi}{ }^{2} / \mathrm{cp}\right)$ \\
\hline 12292.83149 & 6146.415745 & 100 & 614641.5745 & 614641.5745 \\
\hline 24376.28826 & 18334.55987 & 100 & 1833455.987 & 2448097.562 \\
\hline $3.63 \mathrm{E}+04$ & 30320.60355 & 100 & 3032060.355 & 5480157.917 \\
\hline 47970.58322 & 42117.75104 & 100 & 4211775.104 & 9691933.021 \\
\hline 59500.95612 & 53735.76967 & 100 & 5373576.967 & 15065509.99 \\
\hline $1.05 \mathrm{E}+05$ & 82338.46626 & 100 & 8233846.626 & 23299356.61 \\
\hline 123050.7353 & 114113.3558 & 100 & 11411335.58 & 34710692.2 \\
\hline 139592.4511 & 131321.5932 & 100 & 13132159.32 & 47842851.52 \\
\hline 156084.2471 & 147838.3491 & 100 & 14783834.91 & 62626686.42 \\
\hline 172167.9061 & 164126.0766 & 100 & 16412607.66 & 79039294.08 \\
\hline 187788.9995 & 179978.4528 & 100 & 17997845.28 & 97037139.36 \\
\hline 203015.5071 & 195402.2533 & 100 & 19540225.33 & 116577364.7 \\
\hline 217419.7676 & 210217.6373 & 100 & 21021763.73 & 137599128.4 \\
\hline 231440.1819 & 224429.9747 & 100 & 22442997.47 & 160042125.9 \\
\hline 245140.5117 & 238290.3468 & 100 & 23829034.68 & 183871160.6 \\
\hline 258408.3056 & 251774.4086 & 100 & 25177440.86 & 209048601.4 \\
\hline 271222.277 & 264815.2913 & 100 & 26481529.13 & 235530130.6 \\
\hline 283560.9682 & 277391.6226 & 100 & 27739162.26 & 263269292.8 \\
\hline 295405.2167 & 289483.0924 & 100 & 28948309.24 & 292217602.1 \\
\hline 306737.5189 & 301071.3678 & 100 & 30107136.78 & 322324738.8 \\
\hline 316493.8367 & 311615.6778 & 100 & 31161567.78 & 353486306.6 \\
\hline 325371.1615 & 320932.4991 & 100 & 32093249.91 & 385579556.5 \\
\hline 333684.1505 & 329527.656 & 100 & 32952765.6 & 418532322.1 \\
\hline 341438.5016 & 337561.3261 & 100 & 33756132.61 & 452288454.8 \\
\hline 348644.2979 & 345041.3998 & 100 & 34504139.98 & 486792594.7 \\
\hline 355313.7821 & 351979.04 & 100 & 35197904 & 521990498.7 \\
\hline 361453.2641 & 358383.5231 & 100 & 35838352.31 & 557828851 \\
\hline 366724.1437 & 364088.7039 & 100 & 36408870.39 & 594237721.4 \\
\hline 371515.2057 & 369119.6747 & 100 & 36911967.47 & 631149688.9 \\
\hline 375848.3187 & 373681.7622 & 100 & 37368176.22 & 668517865.1 \\
\hline
\end{tabular}


Table A.2- Pseudo-Pressure calculation using the $z$ factor, V iscosity, Compressibility Values from Stimulator (C ont)

\begin{tabular}{|c|c|}
\hline $\mathrm{m}(\mathrm{p}) \times 10^{-6}$ & $\mathrm{p} / \mathrm{z}$ \\
\hline 0.614641574 & 101.1275929 \\
\hline 2.448097562 & 204.5302217 \\
\hline 5.480157917 & 310.2291549 \\
\hline 9.691933021 & 418.2322494 \\
\hline 15.06550999 & 528.5312255 \\
\hline 23.29935661 & 641.0985865 \\
\hline 34.7106922 & 755.8846701 \\
\hline 47.84285152 & 872.8143637 \\
\hline 62.62668642 & 991.7842794 \\
\hline 79.03929408 & 1112.660058 \\
\hline 97.03713936 & 1235.2751 \\
\hline 116.5773647 & 1359.429393 \\
\hline 137.5991284 & 1484.890044 \\
\hline 160.0421259 & 1611.393009 \\
\hline 183.8711606 & 1738.648048 \\
\hline 209.0486014 & 1866.342359 \\
\hline 235.5301306 & 1994.148231 \\
\hline 263.2692928 & 2121.730767 \\
\hline 292.2176021 & 2248.755965 \\
\hline 322.3247388 & 2374.898369 \\
\hline 353.4863066 & 2499.850307 \\
\hline 385.5795565 & 2623.326139 \\
\hline 418.5323221 & 2745.069348 \\
\hline 452.2884548 & 2864.853405 \\
\hline 486.7925947 & 2982.486363 \\
\hline 521.9904987 & 3097.808539 \\
\hline 557.828851 & 3210.69356 \\
\hline 594.2377214 & 3321.044677 \\
\hline 631.1496889 & 3428.793709 \\
\hline 668.5178651 & 3533.896904 \\
\hline & \\
\hline
\end{tabular}


Table A.3- Non-Darcy T urbulence C oefficient, A pparent Skin F actor and Flowing B ottomhole Pseudo-Pressure R esults

\begin{tabular}{|c|c|c|}
\hline $\mathrm{D},(\mathrm{Mscf} / \mathrm{D})^{-1}$ & $\mathrm{~s}^{\prime}$ & $\mathrm{m}\left(\mathrm{p}_{\mathrm{wf}}\right),\left(\mathrm{psi}^{2} / \mathrm{cp}\right)$ \\
\hline $3.74945 \mathrm{E}-05$ & 8.641041079 & $0.00 \mathrm{E}+00$ \\
\hline $3.74945 \mathrm{E}-05$ & & $3.14 \mathrm{E}+08$ \\
\hline $3.74945 \mathrm{E}-05$ & & $3.10 \mathrm{E}+08$ \\
\hline $3.74945 \mathrm{E}-05$ & & $3.07 \mathrm{E}+08$ \\
\hline $3.74945 \mathrm{E}-05$ & & $3.05 \mathrm{E}+08$ \\
\hline $3.74945 \mathrm{E}-05$ & & $3.04 \mathrm{E}+08$ \\
\hline $3.74945 \mathrm{E}-05$ & & $2.99 \mathrm{E}+08$ \\
\hline $3.74945 \mathrm{E}-05$ & & $2.95 \mathrm{E}+08$ \\
\hline $3.74945 \mathrm{E}-05$ & & $2.93 \mathrm{E}+08$ \\
\hline $3.74945 \mathrm{E}-05$ & & $2.89 \mathrm{E}+08$ \\
\hline $3.74945 \mathrm{E}-05$ & & $2.88 \mathrm{E}+08$ \\
\hline $3.74945 \mathrm{E}-05$ & & $2.87 \mathrm{E}+08$ \\
\hline $3.74945 \mathrm{E}-05$ & & $2.85 \mathrm{E}+08$ \\
\hline $3.74945 \mathrm{E}-05$ & & $2.84 \mathrm{E}+08$ \\
\hline $3.74945 \mathrm{E}-05$ & & $2.83 \mathrm{E}+08$ \\
\hline $3.74945 \mathrm{E}-05$ & & $2.82 \mathrm{E}+08$ \\
\hline $3.74945 \mathrm{E}-05$ & & $2.82 \mathrm{E}+08$ \\
\hline $3.74945 \mathrm{E}-05$ & & $2.81 \mathrm{E}+08$ \\
\hline $3.74945 \mathrm{E}-05$ & & $2.80 \mathrm{E}+08$ \\
\hline $3.74945 \mathrm{E}-05$ & & $2.80 \mathrm{E}+08$ \\
\hline $3.74945 \mathrm{E}-05$ & & $2.79 \mathrm{E}+08$ \\
\hline $3.74945 \mathrm{E}-05$ & & $2.79 \mathrm{E}+08$ \\
\hline $3.74945 \mathrm{E}-05$ & & $2.78 \mathrm{E}+08$ \\
\hline $3.74945 \mathrm{E}-05$ & & $2.78 \mathrm{E}+08$ \\
\hline $3.74945 \mathrm{E}-05$ & & $2.78 \mathrm{E}+08$ \\
\hline $3.74945 \mathrm{E}-05$ & & $2.77 \mathrm{E}+08$ \\
\hline $3.74945 \mathrm{E}-05$ & & $2.77 \mathrm{E}+08$ \\
\hline $3.74945 \mathrm{E}-05$ & & $2.75 \mathrm{E}+08$ \\
\hline $3.74945 \mathrm{E}-05$ & & $2.75 \mathrm{E}+08$ \\
\hline $3.74945 \mathrm{E}-05$ & & $2.75 \mathrm{E}+08$ \\
\hline & & \\
\hline & & \\
\hline
\end{tabular}


Table A.4- Flowing B ottomhole Pressure R esults ( $T$ ime $=49.99$ hrs)

\begin{tabular}{|l|}
\hline $\mathrm{p}_{\mathrm{wf}}, \mathrm{psia}$ \\
\hline 1468.42 \\
\hline 1471.01 \\
\hline 1472.28 \\
\hline 1473.08 \\
\hline 1473.65 \\
\hline 1475.12 \\
\hline 1476.16 \\
\hline 1476.58 \\
\hline 1476.90 \\
\hline 1476.96 \\
\hline 1476.98 \\
\hline 1476.97 \\
\hline 1476.91 \\
\hline 1476.85 \\
\hline 1476.77 \\
\hline 1476.69 \\
\hline 1476.61 \\
\hline 1476.53 \\
\hline 1476.45 \\
\hline 1476.37 \\
\hline 1476.28 \\
\hline 1476.21 \\
\hline 1476.13 \\
\hline 1476.05 \\
\hline 1475.97 \\
\hline 1475.90 \\
\hline 1475.55 \\
\hline 1475.52 \\
\hline 1475.48 \\
\hline
\end{tabular}




\section{Table A.5- Skin F actor R esults}

\begin{tabular}{|c|c|c|}
\hline$r_{d}, f t$ & $\mathrm{~s}^{\prime}$ & $\mathrm{S}$ \\
\hline 133.8238 & 8.640078476 & 2.999037 \\
\hline 194.4414 & 8.640046983 & 2.999006 \\
\hline 240.221 & 8.640029161 & 2.998988 \\
\hline 278.5764 & 8.640016674 & 2.998976 \\
\hline 312.2555 & 8.640007054 & 2.998966 \\
\hline 443.8432 & 8.639977412 & 2.998936 \\
\hline 629.2722 & 8.639947985 & 2.998907 \\
\hline 771.3431 & 8.639930826 & 2.99889 \\
\hline 996.4655 & 8.639909239 & 2.998868 \\
\hline 1091.756 & 8.639901541 & 2.99886 \\
\hline 1179.371 & 8.639895034 & 2.998854 \\
\hline 1409.921 & 8.639879983 & 2.998839 \\
\hline 1544.62 & 8.639872292 & 2.998831 \\
\hline 1668.479 & 8.63986579 & 2.998825 \\
\hline 1783.759 & 8.639860158 & 2.998819 \\
\hline 1892.028 & 8.639855191 & 2.998814 \\
\hline 1994.428 & 8.639850748 & 2.99881 \\
\hline 2091.822 & 8.639846729 & 2.998806 \\
\hline 2184.878 & 8.63984306 & 2.998802 \\
\hline 2274.129 & 8.639839685 & 2.998799 \\
\hline 2360.008 & 8.639836561 & 2.998795 \\
\hline 2442.869 & 8.639833652 & 2.998793 \\
\hline 2523.011 & 8.639830931 & 2.99879 \\
\hline 2600.684 & 8.639828375 & 2.998787 \\
\hline 2676.104 & 8.639825965 & 2.998785 \\
\hline 2749.455 & 8.639823686 & 2.998783 \\
\hline 3090.206 & 8.639813837 & 2.998773 \\
\hline 3122.236 & 8.639812968 & 2.998772 \\
\hline 3153.941 & 8.639812116 & 2.998771 \\
\hline
\end{tabular}


APPE NDIX B - Determining F low $R$ ate using T ransient $R$ adial F low Solution Results 
T able B .1- Flow R ates using Pressure Transient Solution R esults ( $\mathrm{Pr}=1500$ psia and $\mathrm{t}=49.99 \mathrm{hrs})$

\begin{tabular}{|c|c|c|c|}
\hline $\mathrm{a}$ & $\mathrm{b}$ & $\mathrm{c}$ & $\mathrm{q}, \mathrm{Mscf} / \mathrm{D}$ \\
\hline 0.0028791 & 528.8340093 & -86680376.58 & 104479.1817 \\
\hline 0.0028791 & 557.5201408 & -86680376.58 & 101876.7261 \\
\hline 0.0028791 & 573.7539382 & -86680376.58 & 100446.3942 \\
\hline 0.0028791 & 585.1278091 & -86680376.58 & 99462.09596 \\
\hline 0.0028791 & 593.8908331 & -86680376.58 & 98713.60632 \\
\hline 0.0028791 & 620.8910399 & -86680376.58 & 96460.27469 \\
\hline 0.0028791 & 647.6948942 & -86680376.58 & 94300.13717 \\
\hline 0.0028791 & 663.3252617 & -86680376.58 & 93074.7091 \\
\hline 0.0028791 & 682.987572 & -86680376.58 & 91567.98379 \\
\hline 0.0028791 & 689.9998562 & -86680376.58 & 91039.83205 \\
\hline 0.0028791 & 695.9269734 & -86680376.58 & 90597.12834 \\
\hline 0.0028791 & 709.63647 & -86680376.58 & 89586.02873 \\
\hline 0.0028791 & 716.6423381 & -86680376.58 & 89076.19036 \\
\hline 0.0028791 & 722.5648743 & -86680376.58 & 88648.76162 \\
\hline 0.0028791 & 727.6946765 & -86680376.58 & 88281.16695 \\
\hline 0.0028791 & 732.2191248 & -86680376.58 & 87958.95668 \\
\hline 0.0028791 & 736.2661294 & -86680376.58 & 87672.33008 \\
\hline 0.0028791 & 739.9269058 & -86680376.58 & 87414.33746 \\
\hline 0.0028791 & 743.2687938 & -86680376.58 & 87179.87414 \\
\hline 0.0028791 & 746.3429255 & -86680376.58 & 86965.08179 \\
\hline 0.0028791 & 749.1890422 & -86680376.58 & 86766.97414 \\
\hline 0.0028791 & 751.8386456 & -86680376.58 & 86583.1932 \\
\hline 0.0028791 & 754.3171288 & -86680376.58 & 86411.84502 \\
\hline 0.0028791 & 756.6452602 & -86680376.58 & 86251.38571 \\
\hline 0.0028791 & 758.8402429 & -86680376.58 & 86100.54044 \\
\hline 0.0028791 & 760.9164862 & -86680376.58 & 85958.24452 \\
\hline 0.0028791 & 769.887244 & -86680376.58 & 85347.75327 \\
\hline 0.0028791 & 770.6789974 & -86680376.58 & 85294.20689 \\
\hline 0.0028791 & 771.4547515 & -86680376.58 & 85241.79501 \\
\hline & & & \\
\hline
\end{tabular}


APPE NDIX C - Determining Skin F actor and Flow R ate using Linear

\section{Flow Solution R esults}


Table C .1- Skin F actors and F low R ates using L inear Flow E quation under nonDarcy R esults ( $K=100 \mathrm{md}, \mathrm{P}=1500 \mathrm{psia}$ and $\mathrm{T}$ ime $=4 \mathrm{hrs}$ )

\begin{tabular}{|c|c|c|c|c|}
\hline $\mathrm{S}_{\mathrm{d}}$ & $\mathrm{L}_{\mathrm{f}}, \mathrm{ft}$ & $\mathrm{t}_{\mathrm{D}}$ & $\alpha$ & $\mathrm{D}_{\mathrm{f}}$ \\
\hline 3.00 & 50.00 & $2.03 \mathrm{E}+00$ & $1.35 \mathrm{E}+00$ & $2.35 \mathrm{E}-07$ \\
\hline 3.00 & 45.00 & $2.50 \mathrm{E}+00$ & $1.37 \mathrm{E}+00$ & $2.66 \mathrm{E}-07$ \\
\hline 3.00 & 40.00 & $3.17 \mathrm{E}+00$ & $1.39 \mathrm{E}+00$ & $3.04 \mathrm{E}-07$ \\
\hline 3.00 & 35.00 & $4.14 \mathrm{E}+00$ & $1.42 \mathrm{E}+00$ & $3.53 \mathrm{E}-07$ \\
\hline 3.00 & 30.00 & $5.64 \mathrm{E}+00$ & $1.44 \mathrm{E}+00$ & $4.18 \mathrm{E}-07$ \\
\hline 3.00 & 25.00 & $8.12 \mathrm{E}+00$ & $1.46 \mathrm{E}+00$ & $5.09 \mathrm{E}-07$ \\
\hline 3.00 & 20.00 & $1.27 \mathrm{E}+01$ & $1.48 \mathrm{E}+00$ & $6.46 \mathrm{E}-07$ \\
\hline 3.00 & 15.00 & $2.25 \mathrm{E}+01$ & $1.50 \mathrm{E}+00$ & $8.74 \mathrm{E}-07$ \\
\hline 3.00 & 10.00 & $5.07 \mathrm{E}+01$ & $1.53 \mathrm{E}+00$ & $1.33 \mathrm{E}-06$ \\
\hline 3.00 & 5.00 & $2.03 \mathrm{E}+02$ & $1.55 \mathrm{E}+00$ & $2.70 \mathrm{E}-06$ \\
\hline
\end{tabular}

\begin{tabular}{|c|c|c|c|}
\hline $\mathrm{a}$ & $\mathrm{b}$ & $\mathrm{C}$ & $\mathrm{q}, \mathrm{Mscf} / \mathrm{D}$ \\
\hline $1.81 \mathrm{E}-01$ & $4.24 \mathrm{E}+06$ & $-8.67 \mathrm{E}+11$ & $2.03 \mathrm{E}+05$ \\
\hline $2.04 \mathrm{E}-01$ & $4.46 \mathrm{E}+06$ & $-8.67 \mathrm{E}+11$ & $1.93 \mathrm{E}+05$ \\
\hline $2.33 \mathrm{E}-01$ & $4.73 \mathrm{E}+06$ & $-8.67 \mathrm{E}+11$ & $1.82 \mathrm{E}+05$ \\
\hline $2.71 \mathrm{E}-01$ & $5.07 \mathrm{E}+06$ & $-8.67 \mathrm{E}+11$ & $1.69 \mathrm{E}+05$ \\
\hline $3.21 \mathrm{E}-01$ & $5.53 \mathrm{E}+06$ & $-8.67 \mathrm{E}+11$ & $1.55 \mathrm{E}+05$ \\
\hline $3.91 \mathrm{E}-01$ & $6.18 \mathrm{E}+06$ & $-8.67 \mathrm{E}+11$ & $1.39 \mathrm{E}+05$ \\
\hline $4.96 \mathrm{E}-01$ & $7.15 \mathrm{E}+06$ & $-8.67 \mathrm{E}+11$ & $1.20 \mathrm{E}+05$ \\
\hline $6.71 \mathrm{E}-01$ & $8.76 \mathrm{E}+06$ & $-8.67 \mathrm{E}+11$ & $9.82 \mathrm{E}+04$ \\
\hline $1.02 \mathrm{E}+00$ & $1.20 \mathrm{E}+07$ & $-8.67 \mathrm{E}+11$ & $7.18 \mathrm{E}+04$ \\
\hline $2.07 \mathrm{E}+00$ & $2.17 \mathrm{E}+07$ & $-8.67 \mathrm{E}+11$ & $3.98 \mathrm{E}+04$ \\
\hline
\end{tabular}


Table C .2- Skin F actors and F low $R$ ates using $L$ inear F low E quation under Darcy Flow R esults ( $K=100 \mathrm{md}, \mathrm{P}=1500$ psia and $\mathrm{T}$ ime $=4 \mathrm{hrs}$ )

\begin{tabular}{|c|c|c|c|c|}
\hline $\mathrm{L}_{\mathrm{f}}, \mathrm{ft}$ & $\mathrm{t}_{\mathrm{D}}$ & $\mathrm{q}, \mathrm{Mscf} / \mathrm{D}$ & $\mathrm{m}\left(\mathrm{p}_{\mathrm{wf}}\right)$ & $\mathrm{L}_{\mathrm{f}}, \mathrm{ft}$ \\
\hline 50.00 & $2.03 \mathrm{E}+00$ & $4.47 \mathrm{E}+05$ & 97190784.00 & 50.00 \\
\hline 45.00 & $2.50 \mathrm{E}+00$ & $4.03 \mathrm{E}+05$ & 97190784.00 & 45.00 \\
\hline 40.00 & $3.17 \mathrm{E}+00$ & $3.58 \mathrm{E}+05$ & 97190784.00 & 40.00 \\
\hline 35.00 & $4.14 \mathrm{E}+00$ & $3.13 \mathrm{E}+05$ & 97190784.00 & 35.00 \\
\hline 30.00 & $5.64 \mathrm{E}+00$ & $2.68 \mathrm{E}+05$ & 97190784.00 & 30.00 \\
\hline 25.00 & $8.12 \mathrm{E}+00$ & $2.24 \mathrm{E}+05$ & 97190784.00 & 25.00 \\
\hline 20.00 & $1.27 \mathrm{E}+01$ & $1.79 \mathrm{E}+05$ & 97190784.00 & 20.00 \\
\hline 15.00 & $2.25 \mathrm{E}+01$ & $1.34 \mathrm{E}+05$ & 97190784.00 & 15.00 \\
\hline 10.00 & $5.07 \mathrm{E}+01$ & $8.94 \mathrm{E}+04$ & 97190784.00 & 10.00 \\
\hline 5.00 & $2.03 \mathrm{E}+02$ & $4.47 \mathrm{E}+04$ & 97190784.00 & 5.00 \\
\hline
\end{tabular}


APPE NDIX D- F low R ate versus Time (L inear Darcy, Linear non-D arcy and R adial non-Darcy) 
Figure D.1- Flow $R$ ate vs. Time ( $P=1000$ psia, $K=100 \mathrm{md}$ )

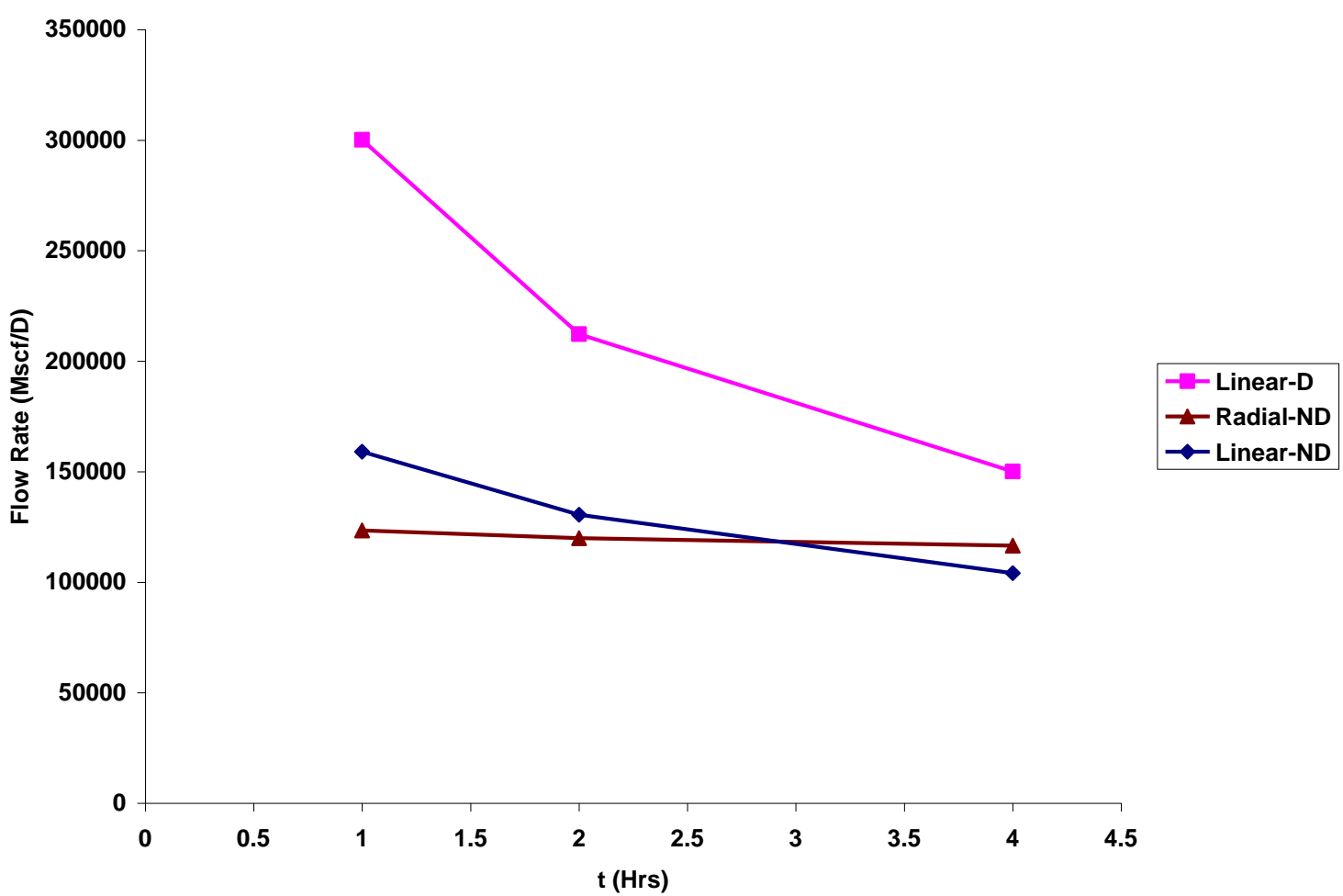


Figure D.2- Flow R ate vs. Time ( $P=1000$ psia, $K=200$ md)

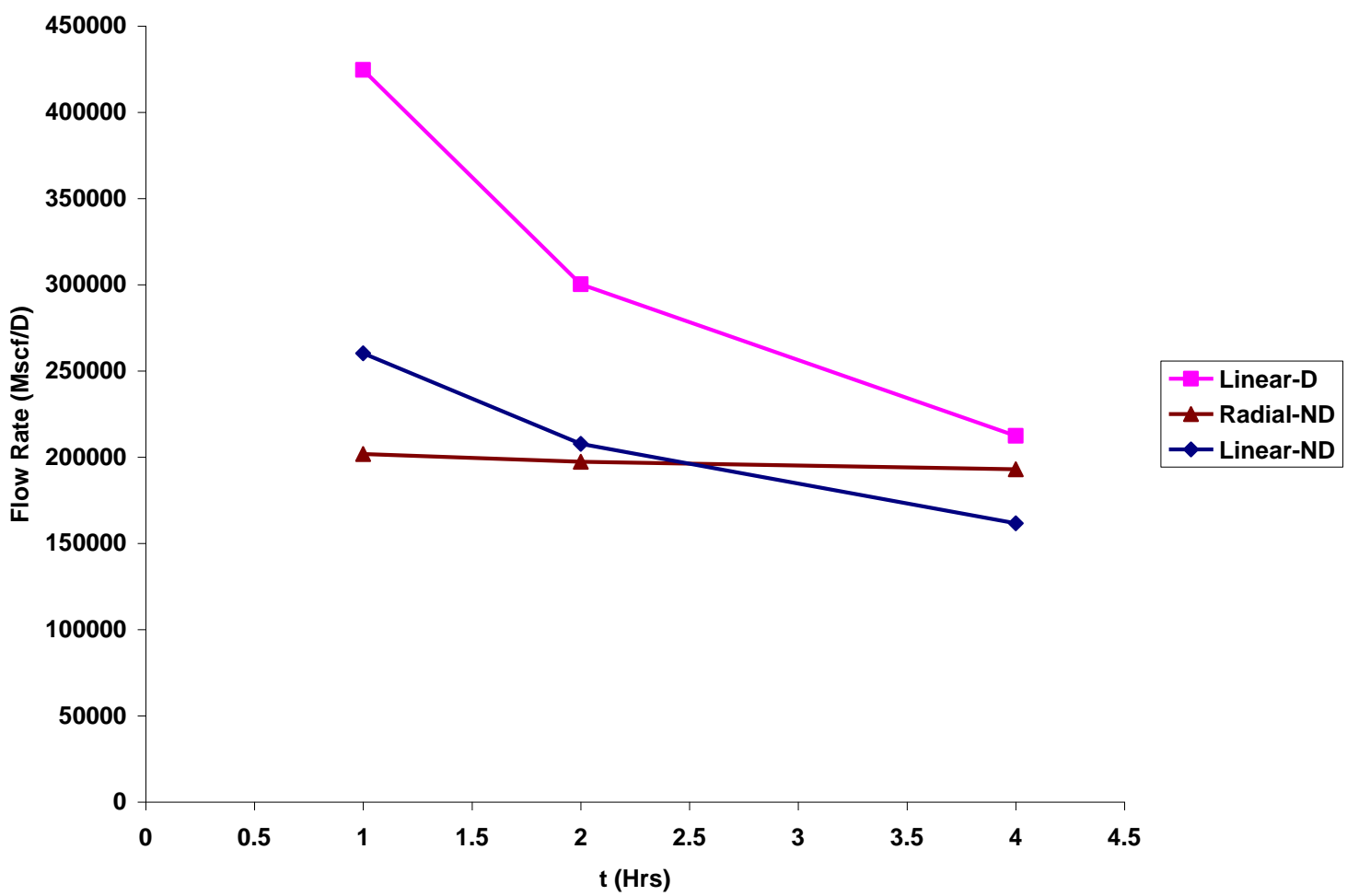


Figure D.3- Flow R ate vs. Time ( $P=1000$ psia, $K=500$ md)

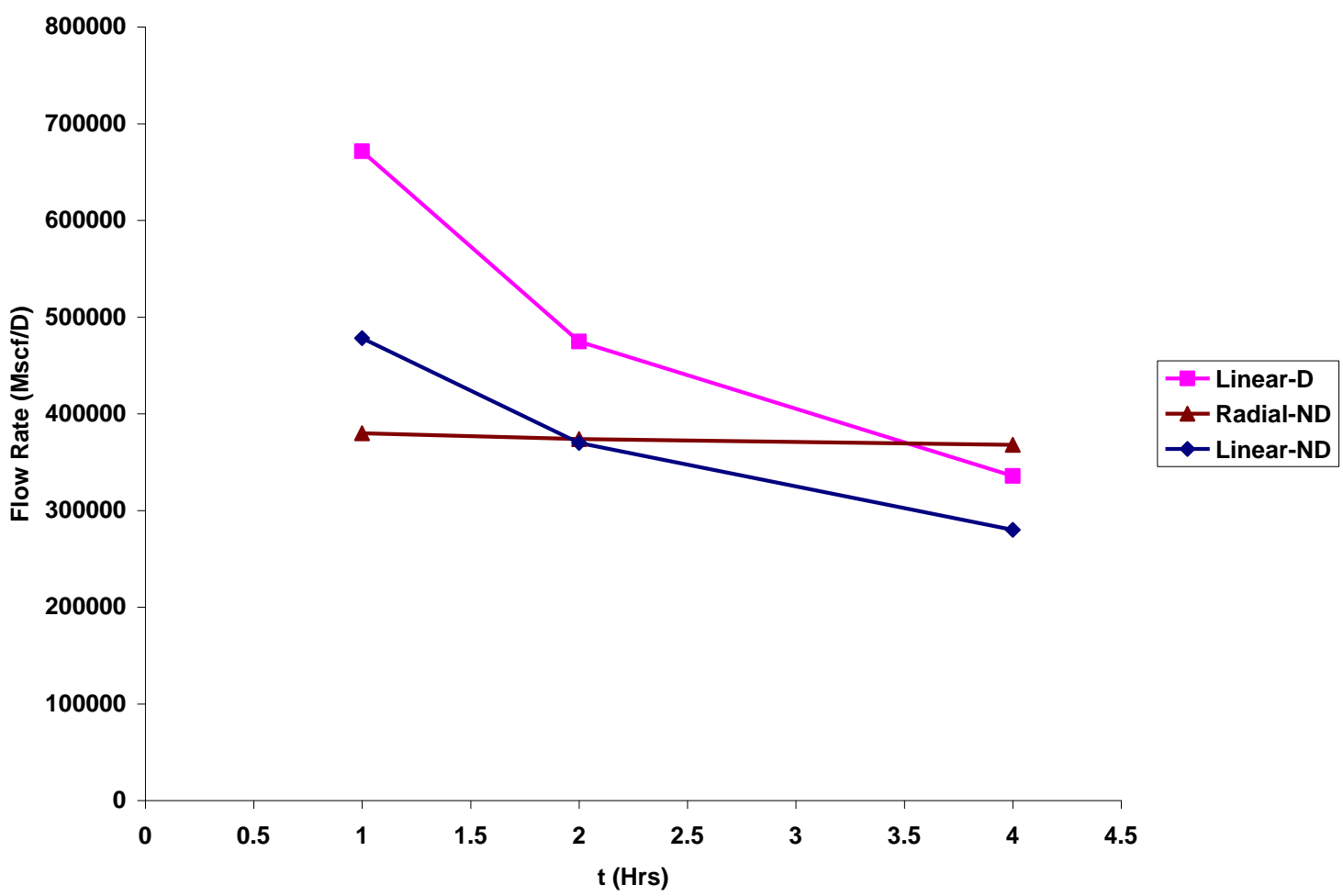


Figure D.4- Flow R ate vs. Time ( $P=1500$ psia, $K=100$ md)

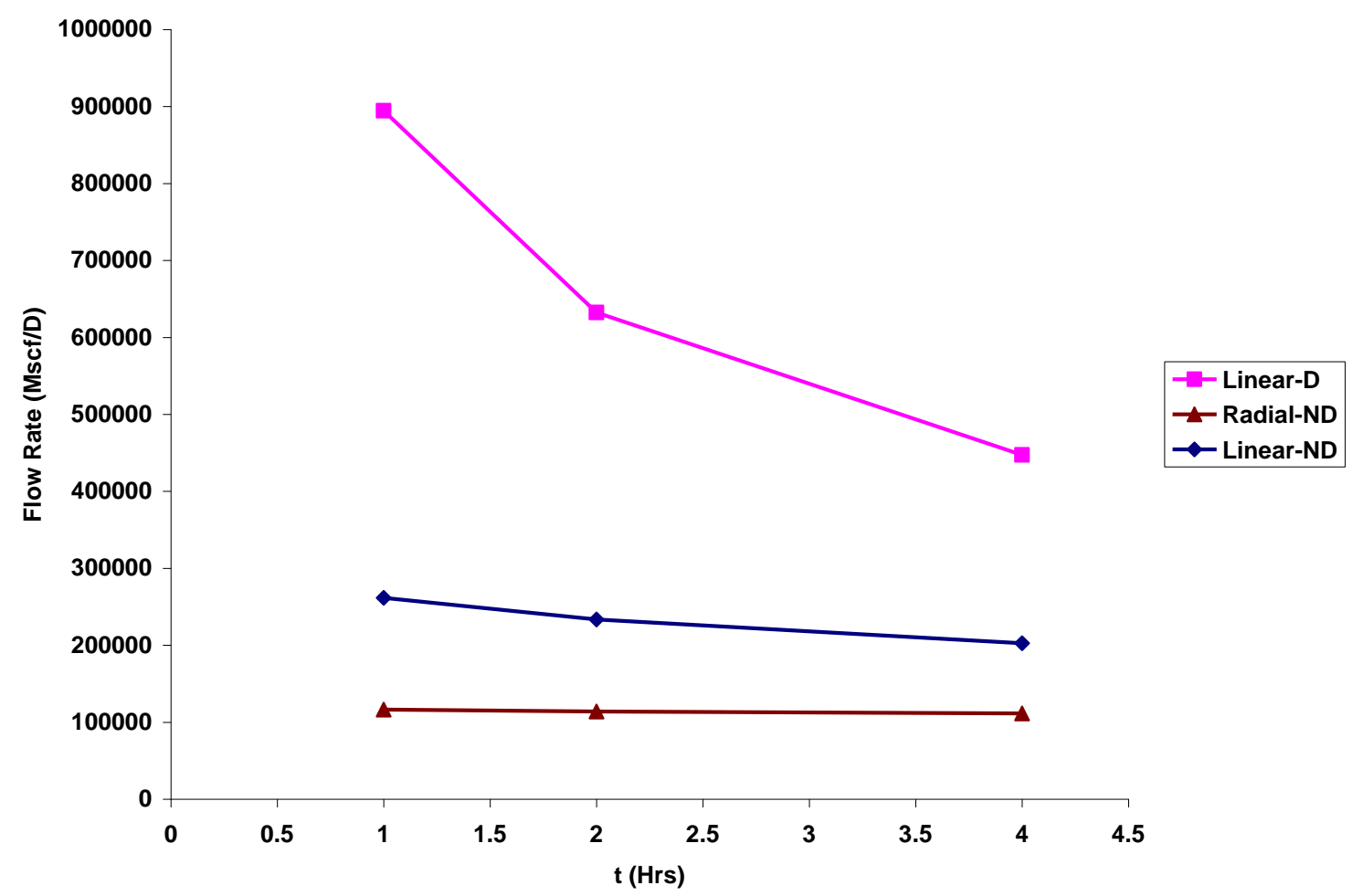


Figure D.5- Flow R ate vs. Time ( $P=1500$ psia, $K=200$ md)

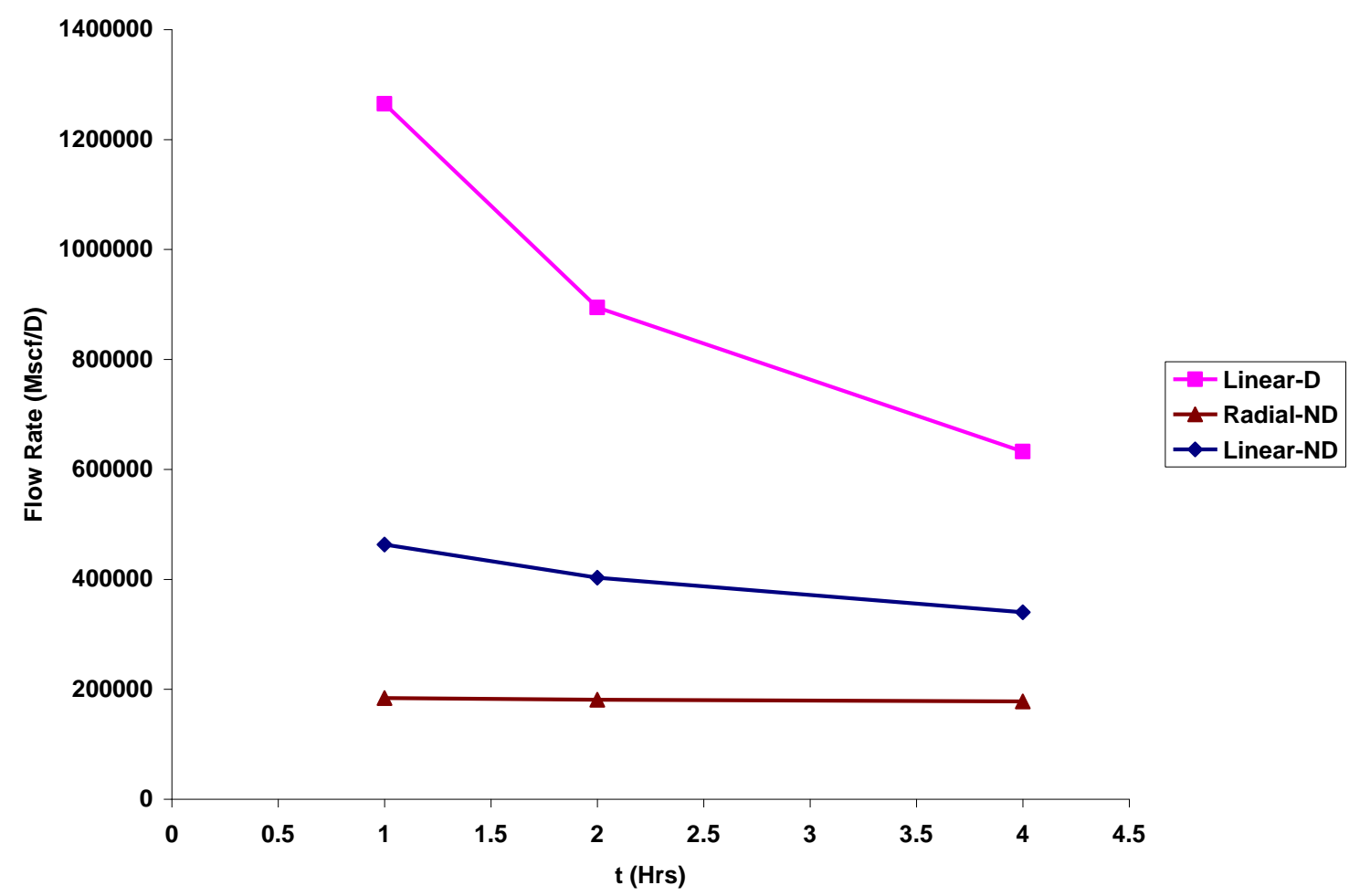


Figure D.6- Flow R ate vs. Time ( $P=1500$ psia, $K=500 \mathrm{md}$ )

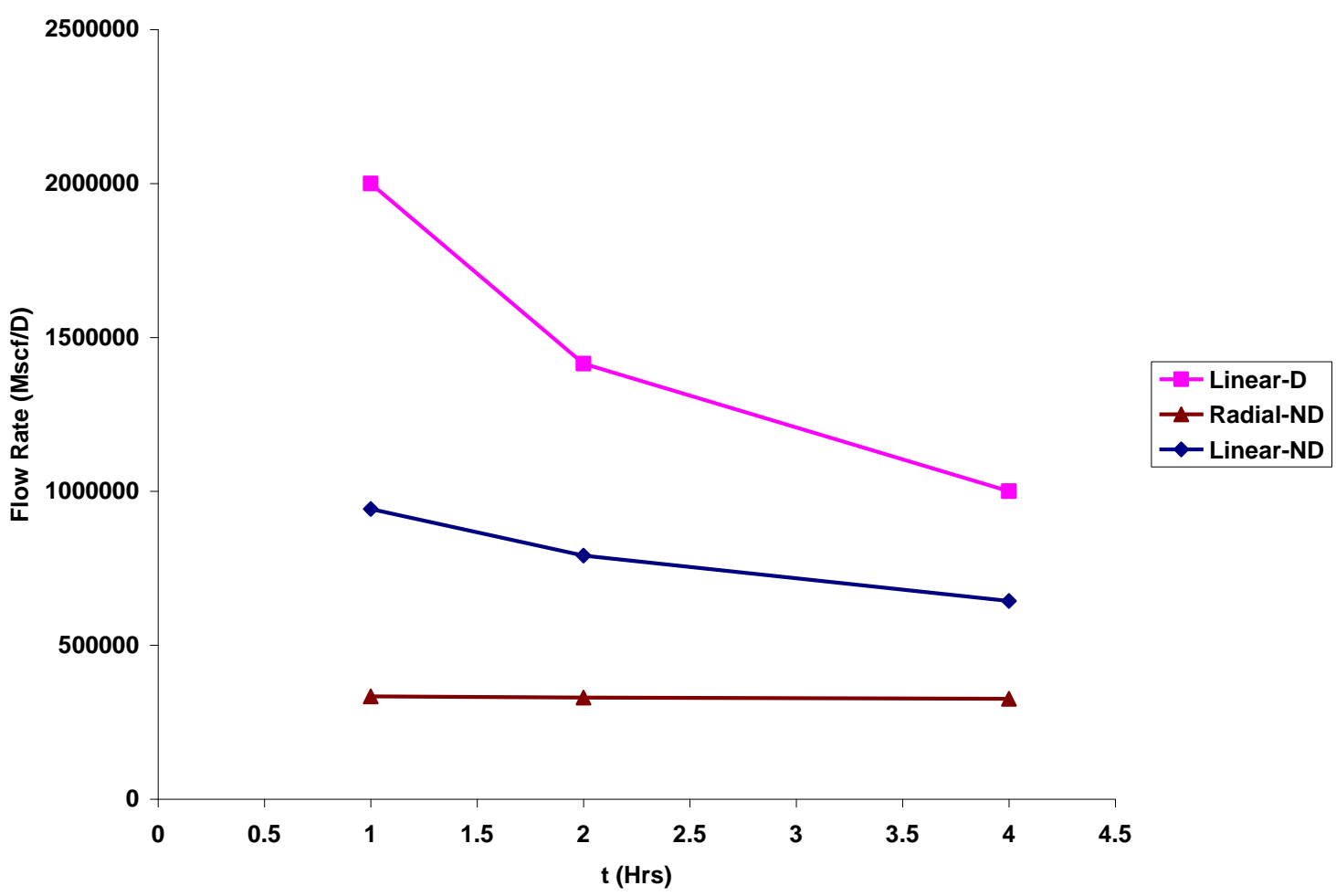


APPE NDIX E - I mpact of Formation Permeability to Deter mine Skin F actor on Transient Radial Flow Solution R esults 
Table E .1- I mpact of Permeability on Skin F actor R esults (R adial Flow)

\begin{tabular}{|c|c|c|c|c|}
\hline $\mathrm{s}$ & $\mathrm{k}, \mathrm{md}$ & $\mathrm{b}_{\mathrm{i}}$ & $\mathrm{b}_{\mathrm{n}}$ & $\mathrm{s}_{\text {new }}$ \\
\hline 0 & 100 & 390.278 & 467.1 & 0.9988506 \\
\hline 0 & 200 & 390.278 & 467.1 & 1.0669555 \\
\hline 0 & 300 & 390.278 & 467.1 & 1.1067943 \\
\hline 0 & 400 & 390.278 & 467.1 & 1.1350604 \\
\hline 0 & 500 & 390.278 & 467.1 & 1.1569853 \\
\hline
\end{tabular}


APPE NDIX F- I mpact of F ormation Permeability to Determine Skin F actor on L inear Flow Solution R esults 
Table F .1- Impact of Permeability on Skin Factor Results (L inear Flow)

\begin{tabular}{|c|c|c|c|c|c|c|c|}
\hline $\mathrm{s}_{\mathrm{d}}$ & $\mathrm{s}_{\mathrm{f}}$ & $\mathrm{x}_{\mathrm{f}}, \mathrm{ft}$ & $\mathrm{t}_{\mathrm{d}}$ & $\mathrm{s}$ & $\mathrm{k}, \mathrm{md}$ & $\mathrm{b}_{\mathrm{i}}$ & $\mathrm{b}_{\mathrm{n}}$ \\
\hline 0 & -3 & 50 & $5.07 \mathrm{E}-01$ & -3 & 100 & 1.26203 & 3.26203 \\
\hline 0 & -3 & 50 & $5.07 \mathrm{E}-01$ & -3 & 200 & 1.26203 & 3.26203 \\
\hline 0 & -3 & 50 & $5.07 \mathrm{E}-01$ & -3 & 300 & 1.26203 & 3.26203 \\
\hline 0 & -3 & 50 & $5.07 \mathrm{E}-01$ & -3 & 400 & 1.26203 & 3.26203 \\
\hline 0 & -3 & 50 & $5.07 \mathrm{E}-01$ & -3 & 500 & 1.26203 & 3.26203 \\
\hline
\end{tabular}

\begin{tabular}{|c|}
\hline$\left(\mathrm{s}_{\mathrm{d}}\right)_{\text {new }}$ \\
\hline 2 \\
\hline 2.828427125 \\
\hline 3.464101615 \\
\hline 4 \\
\hline 4.472135955 \\
\hline
\end{tabular}

